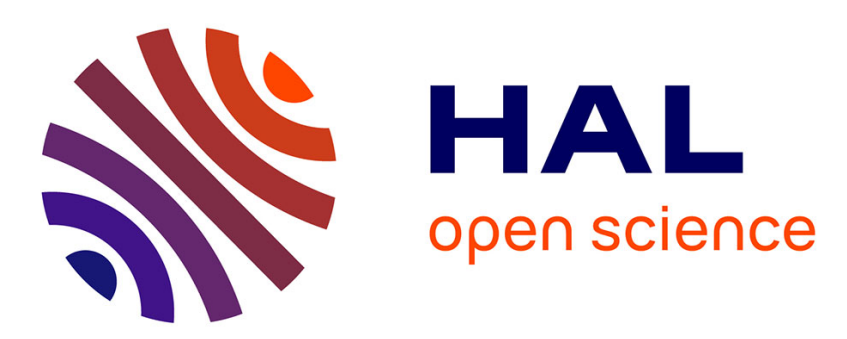

\title{
Experience Transmission: Truth-telling Adoption in Matching
}

Min Zhu

\section{- To cite this version:}

| Min Zhu. Experience Transmission: Truth-telling Adoption in Matching. 2015. halshs-01176926

\section{HAL Id: halshs-01176926 \\ https://shs.hal.science/halshs-01176926}

Preprint submitted on 16 Jul 2015

HAL is a multi-disciplinary open access archive for the deposit and dissemination of scientific research documents, whether they are published or not. The documents may come from teaching and research institutions in France or abroad, or from public or private research centers.
L'archive ouverte pluridisciplinaire HAL, est destinée au dépôt et à la diffusion de documents scientifiques de niveau recherche, publiés ou non, émanant des établissements d'enseignement et de recherche français ou étrangers, des laboratoires publics ou privés. 
UMR 5824

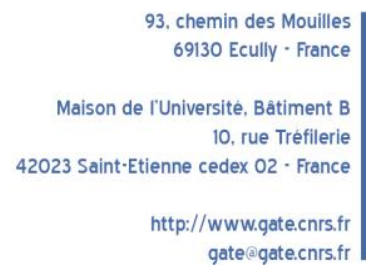

WP 1518 - June 2015

\title{
Experience Transmission: Truth-telling Adoption in Matching
}

\author{
Min Zhu
}

\begin{abstract}
:
Boundedly rational people may engage in strategic behavior under the Deferred Acceptance mechanism, resulting in unstable outcome and reducing overall welfare. How to reduce strategic behavior is thus of importance for field implementation. I address this issue in a laboratory experiment by looking at whether experienced people can transmit what they have learned and promote truth-telling behavior. In this experiment, subjects repeatedly play the matching game induced by the Deferred Acceptance mechanism for a finite number of periods, and then offer advice about best strategies to their successors. Participants in succeeding sessions are either given advice from their predecessors or observe histories of previous sessions. I find that advice given by predecessors can help subjects coordinate on truth-telling behavior and the Pareto efficient stable outcome (but this effect is not statistically significant in correlated preference environment). On the contrary, observing histories has ambiguous effect on truth-telling adoption. This implies that policy makers can encourage real people to adopt truth-telling in the field by providing them with collections of good advice from people who have already participated in matching market.
\end{abstract}

\section{Keywords:}

deferred acceptance mechanism, matching, experiment, experience transmission.

JEL codes:

C78, C92, D47, D82

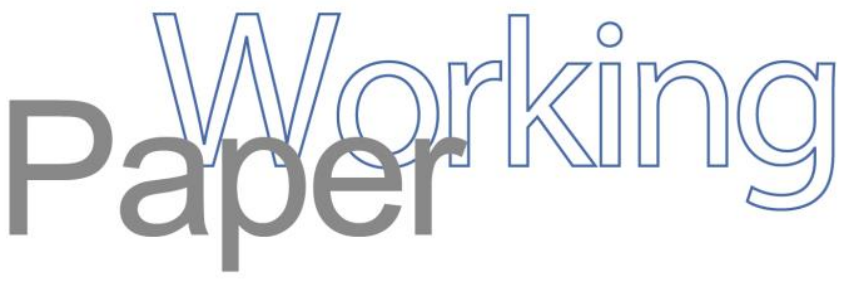




\title{
Experience Transmission: Truth-telling Adoption in Matching *
}

\author{
Min Zhu
}

July 8, 2015

\begin{abstract}
Boundedly rational people may engage in strategic behavior under the Deferred Acceptance mechanism, resulting in unstable outcome and reducing overall welfare. How to reduce strategic behavior is thus of importance for field implementation. I address this issue in a laboratory experiment by looking at whether experienced people can transmit what they have learned and promote truth-telling behavior. In this experiment, subjects repeatedly play the matching game induced by the Deferred Acceptance mechanism for a finite number of periods, and then offer advice about best strategies to their successors. Participants in succeeding sessions are either given advice from their predecessors or observe histories of previous sessions. I find that advice given by predecessors can help subjects coordinate on truth-telling behavior and the Pareto efficient stable outcome (but this effect is not statistically significant in correlated preference environment). On the contrary, observing histories has ambiguous effect on truth-telling adoption. This implies that policy makers can encourage real people to adopt truth-telling in the field by providing them with collections of good advice from people who have already participated in matching market.
\end{abstract}

Keywords: deferred acceptance mechanism, matching, experiment, experience transmission JEL Classification: C78, C92, D47, D82

${ }^{*}$ Université de Lyon, Lyon, F-69007, France; CNRS, GATE Lyon Saint-Etienne, 93 Chemin des Mouilles, F-69130 Ecully, France. Email: zhu@ gate.cnrs.fr. I am extremely grateful to Stéphane Robin for the encouragement, guidance, and helpful suggestions. I am grateful to Jordi Brandts, Francis Bloch, David Copper, Nicolas Houy, Dorothea Kübler, Marie-Claire Villeval, Adam Zylbersztejn, members of BEE group, Conference on Economics Design (2015) for helpful discussions and comments. I would like to thank Yannick Boireaud for excellent research assistance, and Quentin Thevenet for helping with programing. The financial support from the Agence Nationale de la Recherche under contract ANR-13-BSHS1-0010 is gratefully acknowledged. This research was performed within the framework of the LABEX CORTEX (ANR-11-LABX-0042) of Université de Lyon, within the program Investissements d'Avenir (ANR-11-IDEX-007) operated by the French National Research Agency (ANR). 


\section{Instruction}

Mechanisms are usually properly designed by theorists with the goal of fixing real-life problem, such as achieving market efficiency, or eliciting participants' true preferences, etc. However, while theory usually assumes that people have enough cognitive resources and abilities to respond optimally to incentives imposed by designers, real people may perceive wrongly about the mechanism or have difficulties in finding their best strategies (see e.g., Kagel et al. (1987); Attiyeh et al. (2000); Echenique et al. (2014)), which may result in outcomes that are far from the goal of the design. Whether real people are able to behave optimally, and if not, how to find an additive procedure to promote optimal strategies is thus of paramount importance for the real-life implementation of the mechanism. In this paper, I address this question by investigating one widely used mechanism in matching problem, namely the Deferred Acceptance mechanism proposed by Gale and Shapley (1962a).

In recent years, the Deferred Acceptance mechanism (henceforth DA) has been increasingly adopted in numerous matching markets, such as National Resident Matching Program for American medical interns (Roth, 1984; Roth and Peranson, 1999), or the assignment of students to school seats in Boston and New York City (Abdulkadiroğlu et al., 2005a b). The growing popularity of the DA mechanism is mainly attributed to its appealing theoretical properties. First, the DA mechanism always produces a stable outcome with respect to submitted preferences, which proves to be important for the success of centralized matching market (Roth, 1991; Kagel and Roth, 2000). If everyone plays truthfully, this outcome is also the most preferred stable outcome for all agents on the proposing side. Moreover, from incentive perspective, the DA mechanism is strategy-proof for agents on the proposing side $1^{1}$ i.e., it is a weakly dominant strategy for agents on the proposing side to reveal their true preferences. Therefore, the DA mechanism makes it safe for agents to participate the market and to play straightforwardly, as opposed to transacting outside of the market or engaging in strategic behavior that reduces overall welfare (Roth, 2008). Strategy-proofness also "levels the playing field" that the DA mechanism never hurts naïve truth teller (Pathak and Sönmez, 2008) $:^{2}$

\footnotetext{
${ }^{1}$ People on the receiving side have an incentive to misrepresent their true preferences under the Deferred Acceptance mechanism (Dubins and Freedman, 1981, Roth, 1982). However, the receivers' incentive for misrepresentation vanishes as the market grows (Immorlica and Mahdian, 2005, Kojima and Pathak, 2009) and the Deferred Acceptance mechanism is strategy-proof for both sides in the large market (Azevedo and Budish 2012).

${ }^{2}$ In this paper, I am particular interested in agent's behavior on the proposing side. There are two reasons. First, agents on the proposing side are individuals whose behaviors and welfare often need be taken into account (e.g., medical graduates in NRMP or students in public school choice system). Second, some theoretical and empirical studies show that agents on the receiving side always play truthfully whenever the market size is small (Echenique et al. 2014; Featherstone and Mayefsky, 2014) or large (Roth and Peranson, 1999; Azevedo and Budish, 2012). For convenience of discussion, I will mainly focus on one-sided matching problem where only proposers are active agents in this paper. This study also works for two-sided matching problem when agents on the receiving side are assumed to always play truthfully.
} 
Contrary to theoretical predictions, however, experimental data from controlled laboratories show that real people on the proposing side do not always play truthfully. For instance, while truth-telling rate is $88.2 \%$ when subjects have no information about market structure (Pais and Pintér, 2008), only $33.8 \%$ of subjects on the proposing side make offers according to their true preferences in dynamic DA process and in complete information setting (Echenique et al., 2014). Other factors such as risk attitude (Klijn et al., 2013, Ding and Schotter, 2014), cardinal incentives (Klijn et al., 2013), market size (Chen et al., 2014) and market complexity (Chen and Kesten, 2014; Echenique et al., 2014) also have significant effects on truth-telling behavior, which should not be the case as it is a dominant strategy under the Deferred Acceptance mechanism.

In fact, the DA mechanism is a complex process which takes multiple steps to generate the final outcome 3 Ensuring that people have a clear understanding of how the DA mechanism works is somewhat difficult. Meanwhile, strategy sets are also large in matching game as player's strategies consist of preference orderings and strategy profiles are the combinations of all possible orderings $\stackrel{4}{4}^{4}$ Therefore, boundedly rational players may not correctly respond to the incentives faced by them, but to follow some rules of thumbs instead. In fact, empirical data have shown that a substantial number of players misrepresent their preferences considering the likelihood of matching (e.g., "skipping down" behavior (Echenique et al., 2014), 5 small school bias (Chen and Sönmez, 2006, Calsamiglia et al., 2010) 6 district school bias (Chen and Sönmez, 2006; Pais and Pintér, 2008; Chen and Kesten, 2014).77. On the other hand, truth-telling is a weakly dominant strategy and there exists multiple Nash equilibria in the matching game induced by the DA mechanism. In this circumstance, agents may choose to report non-truthful preference rankings which have the equal earning as truth-telling behavior. If some misrepresentation heuristics (e.g., district school bias) happen to be payoff equivalent to truth-telling. ${ }^{8}$ players may stick to these strategies and not report their preferences truthfully: ? $^{9}$

Such preference misrepresentation is a concern because participant's strategic behavior may lead to the outcome that is unstable, and reduce welfare as well. For example, Echenique et al. (2014) show that misrepresenting true preference is a consistent pattern in a variety of matching

\footnotetext{
${ }^{3}$ I will formally present the DA mechanism in section 3 .

${ }^{4}$ For example, when matching market only has three participants and three objects to be allocated, the number of strategy profiles is already $(3 !)^{3}=216$. If further increasing the market size to thousands or millions of participants as that in the real-life matching market, there will be an enormous number of strategy profiles.

${ }^{5}$ That is, subjects skip highly ranked matching partners who are likely to reject them.

${ }^{6}$ That is, subjects put schools with fewer slots into lower positions than those in truthful preference rankings in school choice problem.

${ }^{7}$ That is, subjects put district schools which give them higher priorities into higher positions than those in truthful preference rankings in school choice problem.

${ }^{8}$ For example, to report preference truthfully ends up in the same assigned school as to play district school bias for a given student.

${ }^{9}$ Nevertheless, truth-telling may be another possible heuristic strategy (i.e., default option) that confused subjects probably to play, and is perhaps more likely to be selected as focal point as well.
} 
markets, and because of that, half of the markets result in unstable outcomes. Even among those with stable outcomes, a large number of markets end up close to the worst stable outcomes for subjects on the proposing side. Except for stability and efficiency concern, to encourage truthful preference revelation is important also because most empirical studies use ranked lists of choices as preference data to evaluate policy programs (e.g., the quality of public schools) assuming that participants on the proposing side are truth-telling under the strategy-proof mechanism (see e.g., (Budish and Cantillon, 2012; Abdulkadiroğlu et al., 2013)). If misrepresentation is substantial in the field as that in the experiment, estimation and policy evaluation results will be biased as well.

Given the prevalence of misrepresentation observed in the laboratory, the important question is, whether participants are able to learn to play truthfully, or what we can do to promote truthtelling under the DA mechanism. Previous experiments have shown that subjects tend to adopt truth-telling by repeatedly participating in the same matching market several times (Featherstone and Niederle, 2014; Chen and Kesten, 2014). However, as the matching problem is usually a oneshot game, most people in real life just participate once in the same market, and thus have no chance to gain experience like that in the laboratory. On the other hand, people in reality usually seek information from their acquaintances who have participated in previous matching markets, either hearing advice on how to play the game or observing histories from previous matches. It is thus interesting to know whether people in past matches can transmit their experience about best strategies to people in the coming matches, and if so, whether people are more likely to play truthfully when learning from their peers.

I investigate this question experimentally by looking at whether predecessors' experience can be transmitted to new participants and encourage them to reveal their true preferences. In this paper, I first recruit a group of subjects into the laboratory and ask them to play the matching game induced by the Deferred Acceptance mechanism for 15 periods. At the end of the experiment, they are invited to give advice on the best strategies to subjects who will participate in the same experiments and who have the same preferences as themselves. This advice is like the "naïve" advice defined in Schotter (2003). Subjects are paid a certain percentage of what their laboratory successors will earn and thus have the incentive to give sincere advice. I allow subjects to gain enough own experience by letting them repeatedly participate in the same market with different opponents for a number of periods, so that subjects are expected to learn that truth-telling is the best strategy in the end and know what good advice should be given. We then use data from this baseline treatment for two other treatments: the advice treatment and the observation treatment. The advice treatment is the same as the baseline treatment except that at the beginning of the experiment, subjects in the advice treatment are informed of all advice given by their predecessors from the baseline treatment in the form of common knowledge. In the observation treatment, instead of seeing advice, subjects can observe histories of the baseline treatment, including what 
strategies subjects played and the average payoff for playing that strategy in each of 15 periods.

To find out whether predecessors' experience has different effect on truth-telling adoption in different market structures, and to check empirical relation between behaviors and outcomes, the experiment employs two stylized environments. Two environments differ from each other by whether it is possible for participants to have the same earning by misrepresenting first choices as reporting true top choices. In the uncorrelated preference environment, every subject has different interest on their most preferred object, and the Pareto efficient stable outcome can be achieved only if everyone reports their true top choice. Any misrepresentation by ranking less preferred object first will lead to sub-optimal outcome. On the other hand, in the correlated preference environment, due to competition, no one obtains their most preferred object in this stable outcome. Most of the time, some misrepresentation behavior will also result in the same stable outcome as truth-telling. Hence, a certain level of misrepresentation may not affect market's stability and efficiency in the correlated preference environment. Furthermore, both environments have the very small matching scale and subjects are provided with all information about the game, so they are expected to most easily understand the mechanism and realize their best strategies in these simple environments.

There are some interesting findings for this experiment. (1) Even in the simplest environment, there is a large number of subjects misrepresenting their preferences in the first period of the baseline treatment in both environments (i.e., $25 \%$ and $52.8 \%$ of subjects reveal their true preferences in the uncorrelated preference environment and correlated preference environment, respectively). This result is consistent to previous findings in typical one-shot matching game when subjects have no prior experience of their own or from peers. (2) With ample repetition, subjects learn to play truthfully through their own experience, and the majority of them would like to advise on truthtelling as well in both environments (i.e., $80.6 \%$ and $69.4 \%$ of subject advise subjects of their own types to play truthfully in the uncorrelated preference environment and correlated preference environment, respectively). (3) When having advice from their predecessors who have experienced the same matching games, subjects are more likely to adopt truth-telling in both environments. However, this effect is not statistically significant in the correlated preference environment. (4) On the other hand, observing matching histories has a positive effect on truth-telling adoption in the uncorrelated preference environment, but a negative effect in the correlated preference environment. (5) Consequently, due to positive correlation of truth-telling and payoff, subjects are more likely to coordinate on Pareto efficient outcome in the advice treatment and in the observation treatment of the uncorrelated preference environment. However, as incentive to play truthfully is relatively weak, behaviors changes in the correlated preference environment has no significant effect on stability and efficiency.

These results indicate that advice given by experienced participants is a good device for experience transmission, helping participants coordinate on truth-telling behavior and the Pareto efficient 
stable outcome. In fact, a number of laboratory experiments show that the advice from predecessors has proven a very powerful force in shaping people's behaviors in many contexts, such as creating convention in the the Battle of the Sexes Game (Schotter and Sopher, 2003), the ultimatum game (Schotter and Sopher, 2007) and the trust game (Schotter and Sopher, 2006), or improving coordination on payoff-dominant outcome (Chaudhuri et al., 2006, 2009), or encouraging strong-performing women to entry into competition (Brandts et al.).

Until just recently, I am aware that Ding and Schotter (2015) also investigate the question of intergeneration advice in matching market lately. In their experiment, differing from this paper, subjects engage in the matching mechanism just once and are replaced by a new generation who involve in the same game. At the end of each round, subjects pass on advice to next generation about how to behave. Contrary to this paper, they find that surprisingly, with this type of social learning, truth-telling rate significantly decreases over time under the DA mechanism. Whereas they try to mimic the real world where participants pass on advice generation by generation with lack of experience, this paper focuses on how to design a policy to promote truth-telling. Letting participants gain enough experience to know what best strategy should suggest, I investigate whether good experience can be successfully transmitted and help participants adopt truth-telling behavior.

The rest of the paper is organized as follows. Section 2 reviews literature on the Deferred Acceptance mechanism as well as other famous strategy-proof mechanisms, with particular attention to how real people behave differently from what theory predict. Section 3 formulates the matching model and the Deferred Acceptance mechanism. Theoretical properties of the Deferred Acceptance mechanism are also presented in this section. In section 4, I present experiment design and experimental hypothesis. Section 5 presents results both at the individual level and the aggregate level in the uncorrelated preference environment and correlated preference environment, respectively. Finally, Section 6 concludes.

\section{Literature Review}

There have been a number of laboratory studies showing that subjects do not behave as theory predicts in some important strategy-proof mechanism mechanisms. For example, in the secondprice sealed-bid auction, while each player has a dominant strategy to bid their true value, a number of experiments have shown that most bidders bid their values higher than true values (see e.g., Kagel et al. (1987); Kagel and Levin (1993); Harstad (2000)). The prevalence of overbidding in the second price auction is mainly attributed to the less transparency of dominant strategy, as

well as weak feedback of discouraging overbidding as it is not punished with losses (Kagel and Levin, 1993). Moreover, experience from other institutions has an effect on bidding strategies 
in the second price sealed-bid auction as well. Harstad (2000) documents that subjects with prior experience in English auction are less likely to overbid than those without prior experience. Garratt et al. (2012) show that bidders who are highly experienced in eBay auctions are no more likely to overbid than to underbid, but with inexperienced bidders only very few bids are approximately equal to value.

Another well studied mechanism is the pivotal mechanism in public school game. The pivotal mechanism is one version of the Vickrey-Clarke-Groves (VCG) mechanism (Vickrey, 1961, Clarke, 1971; Groves, 1973), which is strategy-proof in the sense that reporting one's preference truthfully is always a dominant strategy. However, several studies have documented that subjects often fail to play dominant strategies. For example, Attiyeh et al. (2000) find that less than 10 percent of subjects reveal their true values for the public good, and they attribute this poor performance to the complexity of the pivotal mechanism and subject confusion. Kawagoe and Mori (2001) support this interpretation with a controlled experiment. They find that when the context and the mechanism are complex as that in Attiyeh et al. (2000), less than 20 percent of subjects reveal true values. However, when the mechanism is simplified and represented by detailed payoff tables, nearly 50 percent of the subjects play the dominant strategy.

Furthermore, motivated by theoretical notion of secure implementation introduced in Sjostrom et al. (2007), Cason et al. (2006) conjecture that the low truth-telling rates in the second price sealed-bid auction and in the pivotal mechanism are due to non-secure implementation, in the sense that there are other Nash equilibria differing from the dominant strategy equilibria. They conduct an experiment with the context-free payoff tables to compare the pivotal mechanism with the secure implementation Groves-Clarke mechanism with single-peaked preferences. They find that subjects are significantly more likely to play their dominant strategies in the Groves-Clarke mechanism than those in the pivotal mechanism, indicating that the non-secure implementation of the pivotal mechanism is one systematical reason to explain why many players do not obey dominant strategies.

Studies also show that some people play truthfully not because they understand the strategyproof mechanism but just because the true preference ranking induced in the laboratory is a default option. Guillén and Hing (2013) conduct a laboratory experiment by letting subjects play with payoff maximizing computerized agents under the Top Trading Cycle mechanism. They find that truth-telling rates not only vary with third party advice, but they are also significantly lower in all advice treatments than that in the baseline treatment with no advice. Guillén and Hakimov (2014) also employ a human-robot design to see whether subjects play truthfully due to understanding the incentive or due to a "monkey see monkey do" effect. They find that subjects are more likely to play truthfully when having more information about the strategies played by others. Consequently, these results indicate that there is a large proportion of subjects confused in the laboratory. 
There have been a growing experiments investigating the DA mechanism in recent years, with various research purposes. Although laboratory experiments in matching market show that in most cases, subjects under the DA mechanism are significantly more likely to reveal their truthful preferences than those under non strategy-proof mechanism (e.g., the Boston mechanism), they also present a substantial proportion of misrepresentation under the Deferred Acceptance mechanism. Moreover, the rate of truth-telling (resp. the rate of misrepresentation) varies with environments employed. For example, while truth-telling rate is as high as $88.2 \%$ when subjects have no information about market structure in Pais and Pintér (2008) school choice experiment, only 33.8 percent of subjects on the proposing side make offer in their truthful preferences in Echenique et al. (2014) two-sided matching market, where subjects take actions along the DA process instead of submitting complete preference lists.

Interestingly, whereas theory states that risk attitudes, information, or market structures should have no effect on the behavior of proposing side under the Deferred Acceptance mechanism because truth-telling is a dominant strategy, experiments provide different findings. For example, subjects with high risk aversion are more likely to play truthfully as it is a protective behavior (Klijn et al. 2013). When there is no information about others' payoffs, priorities and capacities of schools (Pais and Pintér, 2008), or when the number of players is sufficiently large (Chen et al. 2014), subjects are also more likely to submit their preferences truthfully. On the contrary, when cardinal difference between the first and second preferred schools increases while keeping ordinal ranking unchanged (Klijn et al., 2013), or when the market has more Nash equilibrium outcomes (Chen and Kesten, 2014), subjects are more likely to misrepresent their true preferences.

Table 1: Representative Experimental Studies on the Deferred Acceptance Mechanism

\begin{tabular}{ccc}
\hline \hline Environment & Truth-telling rate & Paper \\
\hline random preference v.s. correlated preference & $55.6 \%$ v.s. $72.2 \%$ & Chen and Sönmez (2006) \\
partial information v.s. zero information & $66.7 \%$ v.s. 88.2\% & Pais and Pintér (2008) \\
high cardinal intensity v.s. low cardinal intensity & $44.4 \%$ v.s. 64.8\% & Klijn et al. (2013) \\
6 school v.s. 4 school & $46.8 \%$ v.s. $75.1 \%$ & Chen and Kesten (2014) \\
market size $=$ 4 v.s. market size $=4000$ & $60.3 \%$ v.s. 65.9\% & Chen et al. (2014) \\
\hline \hline
\end{tabular}

Previous lab experiments also present some patterns of misrepresentation when subjects do not reveal truthful preferences. For example, subjects are found to play some heuristic strategies such as small school bias (i.e., subjects put schools with fewer slots in lower positions than those in truthful preference rankings), similar preference bias (i.e., subjects put schools with the highest payoffs into lower positions than those in truthful preference rankings) and district school bias (i.e., subjects put their district schools which give them higher priorities into higher positions than those in truthful preference rankings) in school choice problems (Chen and Sönmez, 2006, Pais and Pintér, 2008). In Echenique et al. (2014) two-sided matching experiment, it is prevalent for 
subjects on the proposing side to "skip" highly ranked matching mates who are likely to reject them and put them into lower positions of truthful preference lists. In summary, subjects on the proposing side seem to consider the likelihood of matching and follow some rules of thumb to misrepresent their truthful preferences.

\section{Matching Problem and The Deferred Acceptance mechanism}

\subsection{The Model}

Before presenting experimental design, I will first formulate the game employed in the experiment, and then look at theoretical properties of the DA mechanism that are used for deriving experimental hypotheses in Section 4

Because I am interested in strategic behavior on the proposing side, I will focus on one-sided matching problem. There are two disjoint and finite sets in this model, which consists of the following:

1. a finite set of subjects $S=\left\{s_{1}, s_{2}, \ldots, s_{n}\right\}$, with a general element in $S$ denoted by $s$.

2. a finite set of objects $O=\left\{o_{1}, o_{2}, \ldots, o_{m}\right\} \cup\{\emptyset\}$, where $\emptyset$ denotes a subject's outside option, or so-called null object. A general element in $O$ is denoted by $O$.

3. a quota vector $q=\left(q_{o_{1}}, q_{o_{2}}, \ldots, q_{o_{m}}\right)$, where there are $q_{o}$ identical unites for object $o$. Also let $q_{\emptyset}=\infty$.

4. a list of strict preferences for subjects $P=\left(P_{s}\right)_{s \in S}$ where $P_{s}$ is a strict preference relation of subject $s$ over objects and no-object option.

5. a list of strict priority orders for objects $P=\left(P_{o}\right)_{o \in O}$ where $P_{o}$ is a strict priority order of object $o$ for all subjects.

The sets $S$ and $O$ can represent students and schools. Let $R_{s}$ denote the at-least-as-good-as relation associated with $P_{s}$. Formally, I assume that $R_{s}$ is a linear order, i.e., a complete, transitive, anti-symmetric binary relation on $\mathrm{O}$. That is, for any $o, o^{\prime} \in O, o R_{s} o^{\prime}$ if and only if $o=o^{\prime}$ or $o P_{s} o^{\prime}$. We sometimes write $P_{s}: o_{1}, o_{2}, o_{3}$ to denote that subject $s$ prefers object $o_{1}$ to object $o_{2}$ to object $o_{3}$. And $s_{1}-s_{2}-s_{3}$ represents the strict priority order for subjects in which $s_{1}$ is ranked first, $s_{2}$ is ranked second and $s_{3}$ is ranked third.

Thus a one-sided matching problem is a pair $\left(P=\left(P_{s}\right)_{s \in S}, P=\left(P_{o}\right)_{o \in O}\right)$. Let $\mathcal{R}$ be the set of all problems. A matching is an allocation of objects to subjects such that no subject obtains more than one unite of object. Formally, it is a function $\mu: S \rightarrow O \cup\{\emptyset\}$, such that $\left|\mu^{-1}(o)\right| \leq q_{o}$ for all $o \in O$. Let $\mathcal{M}$ be the set of all matchings.

A matching $\mu$ is Pareto efficient if there is no other matching which makes all subjects at least as well off and at least one subject better off. A matching $\mu$ is stable, i.e., there is no unmatched 
subject-object pair $(s, o)$ such that subject $s$ prefers object $o$ to his allocated object, and either there are available unites for object $o$ or subject $s$ has higher priority than at least one subject who obtains o.

\subsection{The Mechanism}

A mechanism $\varphi$ is a systematic procedure that determines a matching for each matching problem. Formally, it is a function $\varphi: \mathcal{R} \rightarrow \mathcal{M}$. Let $\varphi\left(P_{s}, P_{o}\right)$ denote the matching chosen by $\varphi$ for problem $\left(P_{s}, P_{o}\right)$ and let $\varphi_{s}\left(P_{s}, P_{o}\right)$ denote the allocated object to subject $s$ at this matching. A mechanism is Pareto efficient (stable) if it always selects Pareto efficient (stable) matchings.

This paper investigates the Deferred Acceptance mechanism introduced by Gale and Shapley (1962b), which is a multi-step process that works as follows:

Step 0: Each subject submits his preference list over objects to be allocated.

Step 1: Each subject is selected to be sent to the object which he indicates as first choice. For each object $o$, all subjects who put it as first choice are ranked according to its priority order. The object $o$ is tentatively allocated to subjects who have the highest $s$-priority up to $q_{o}$. The remaining subjects are rejected.

Step $k, k \geq 2$ : Each subject rejected at Step $k-1$ is sent to the object which he indicates as next choice. For each object $o$, all subjects who are selected at Step $k$ are pooled with subjects whom the object are tentatively allocated to at an earlier step and are ranked together according to its priority order. Then the object $o$ is tentatively allocated to subjects who have the highest $s$-priority up to $q_{o}$. The remaining subjects are rejected.

The process continues until there is no subject being rejected or there is no available unite for object. Then all tentative allocations become permanent.

The Deferred Acceptance mechanism has several desirable theoretical properties, most notably stability and strategy-proofness for proposing side. Gale and Shapley (1962b) in their seminal paper prove that there is always a stable matching given any matching problem, and the optimal stable matching for all subjects on the proposing side can be achieved by the Deferred Acceptance mechanism.

Theorem 1 (Gale-Shapley Theorem). The set of stable matchings $M\left(P_{s}, P_{o}\right)$ is non empty, and $\varphi^{D A}\left(P_{s}, P_{o}\right) \in M\left(P_{s}, P_{o}\right)$. Moreover, for all $s \in S$ and all stable matchings $\mu^{\prime} \in M\left(P_{s}, P_{o}\right)$, we have $\varphi_{s}^{D A}\left(P_{s}, P_{o}\right) R_{s} \mu^{\prime}(s)$. 
A mechanism $\varphi$ defines a direct revelation game: the normal-form game where subjects in $S$ simultaneously submit their preferences, so the strategy space of subject $s$ is $\mathcal{P}_{s}$, and the outcome of a profile $P$ is given by $\varphi(P)$. For a subject $s \in S$, truth-telling is a weakly dominant strategy if, for any preference profile $Q_{s}$ different from the true preferences $P_{s}$, and any profile $\tilde{P_{-s}}$ of all subjects but $s, \varphi_{s}\left(P_{s}, \tilde{P_{-s}}\right) R_{s} \varphi_{s}\left(Q_{s}, \tilde{P_{-s}}\right)$.

A mechanism is strategy-proof if truth-telling is weakly dominant for all players. Roth (1982) in his paper proves that in the game induced by the Deferred Acceptance mechanism, it is a weakly dominant strategy for players on the proposing side to play truthfully. As it turns out, we have the following:

Theorem 2 (Strategy Proofness). In the Deferred Acceptance mechanism, truth-telling is a weakly dominant strategy for subjects on the proposing side.

Next, I will present experimental design and hypotheses used for this paper.

\section{Experimental Design}

The experiment is designed to study whether predecessors' experience can be transmitted to new participants and encourage them to reveal their true preferences under the Deferred Acceptance mechanism.

A $2 \times 3$ factorial design is implemented in two experimental environments, the uncorrelated preference environment and the correlated preferencce enviornment, with three different settings: the baseline treatment, the advice treatment and the observation treatment. In the baseline treatment, subjects repeatedly participate in the game induced by the Deferred Acceptance mechanism for 15 periods, and are invited to give advice about what is the best strategy at the end of experiment. Participants in succeeding sessions are either given advice left by participants in the baseline treatment or can observe what strategies they have played and average payoffs for playing different strategies at the beginning of the experiment, and then repeat the same game for 15 periods. The game is employed in the complete information setting so that I can compute Nash equilibrium strategies and outcomes. While incomplete information might be more realistic, it is useful to start investigation from the complete information setting.

\subsection{Economic Environment}

The experiment is designed under the one-sided matching problem framework, as I am mainly interested in behaviors of the proposing side. This study can also be viewed as the two-sided matching problem when receivers are computerized agents who always play truthfully. In fact, some two-sided matching experiments (Echenique et al., 2014; Featherstone and Mayefsky, 2014) 
show that players on the receiving side always play truthfully in laboratories. Theories also reveal that receivers' incentive for misrepresentation vanishes in large markets (Immorlica and Mahdian, 2005; Kojima and Pathak, 2009). In this case, it is interesting to check whether subjects on the proposing side best respond to truthful receivers.

The experiment employs a very small market scale: In this market, there are three subjects Type1, Type2, Type 3 on the proposing side and three objects $A, B, C$ to be allocated on the other side. This environment is relatively simple for subjects to think through. With the minimum size of strategy sets, fully informed subjects are expected to most easily understand the mechanism and realize their best strategies. In each experimental session, there are 12 subjects of three different types. At the beginning of the experiment, all subjects are randomly assigned into four groups of three. Each group has each of three types. There are three different objects for each group. Each object has one unit to be allocated in each group and is acceptable to all subjects. Therefore, there is no subject left with no allocated object.

To check the empirical relation between behaviors and outcomes, two stylized environments are designed to capture typical market structures used in the real world. The payoffs and priorities for each type of subjects, which are commonly known to all participants, are presented in Table 2 for uncorrelated preference environment, and in Table 3 for correlated preference environment, respectively. The left panel in Table 2 and Table 3 are payoffs for each type of subjects when different objects are allocated to them. Each subject will earn 200 points if they obtains their most preferred object and 40 points if they obtains their least preferred object. Thus there is a substantial payoff difference for different objects to be allocated. The right panel in Table 2 and Table 3 are the priorities that each type of subjects have for different objects to be allocated. For instance, a subject of Type 3 has the highest priority to obtain object A, and a subject of Type 2 has the second highest priority to obtain object A.

Table 2: Uncorrelated Preference Enviornment: Payoffs and Priorities for Each Type of Subjects

\begin{tabular}{ccccccccc}
\hline \hline & \multicolumn{3}{c}{ Payoffs } & & \multicolumn{4}{c}{ Priorities } \\
\cline { 1 - 2 } Type1 & Object A & Object B & Object C & & & 1st & 2nd & 3rd \\
Type2 & 200 & 120 & 40 & & Object A & Type3 & Type2 & Type1 \\
Type3 & 120 & 200 & 120 & & Object B & Type1 & Type3 & Type2 \\
\hline \hline
\end{tabular}


Table 3: Correlated Preference Enviornment: Payoffs and Priorities for Each Type of Subjects

\begin{tabular}{|c|c|c|c|c|c|c|c|}
\hline \multicolumn{4}{|c|}{ Payoffs } & \multicolumn{4}{|c|}{ Priorities } \\
\hline & Object A & Object B & Object C & & $1 \mathrm{st}$ & 2nd & $3 r d$ \\
\hline Type1 & 200 & 120 & 40 & Object A & Type3 & Type2 & Type1 \\
\hline Type2 & 200 & 40 & 120 & Object B & Type1 & Type3 & Type2 \\
\hline Type3 & 120 & 200 & 40 & Object C & Type2 & Type1 & Type3 \\
\hline
\end{tabular}

The uncorrelated preference environment is chosen that each subject has different interest in their most preferred object. Each subject will obtain their most preferred object if everyone lists it as their first choice, which is the Pareto efficient stable outcome. On the other hand, in the correlated preference environment, there is a competition between Type 1 and Type 2 for object $A$, yet Type 3 has the highest priority for this object. In this environment, each subject can only obtain their second preferred object when playing truthfully.

In both environments, no one has the highest priority for their most preferred object, but each subject has the highest priority for their second preferred object. In this case, a particular subject is guaranteed to obtain his second preferred object if ranking it as first choice. One misrepresentation pattern, safety choice bias, is thus defined as the behavior that a subject misrepresents his preference by reporting second preferred object as first choice. If subjects have wrong perception of the DA mechanism or do not understand the dominant strategy, they probably think it is risky to report true top choices (without highest priorities) and may list their second preferred objects (with highest priorities) as first choices instead.

In the uncorrelated preference environment, the Pareto efficient stable outcome can be achieved only if everyone submits their most preferred object as first choice. Playing safety choice bias can only result in a sub-optimal outcome. On the other hand, each subject obtains his second preferred object in the stable outcome under truth-telling in the correlated preference environment. Playing safety choice bias also results in the same stable outcome in this environment.

Three types are randomly assigned to 12 participants at the beginning of the experiment, and the type for each participant remains the same during the experiment. Participants are randomly rematched with each other at the beginning of each period. During the experiment, each participant is asked to submit a list indicating his preference over objects, i.e., his first choice, second choice, and third choice. In order to incentivize participants to play seriously in each period, the final payment is randomly determined from 1 out of 15 periods.

\subsection{Treatment}

To investigate whether subjects would like to transmit what they have learned to their successors, I ask subjects to repeatedly play the matching game induced by the Deferred Acceptance 
mechanism for 15 periods. Subjects are thus able to gain enough experience to learn that truthtelling is in their best interest. After subjects finish the experiment, they are invited to give advice about the best strategy to subjects who will participate in the same experiment in the following sessions and who have the same type as themselves. More precisely, they can give advice about what should be the first choice to submit, what should be the second choice to submit, and what should be the third choice to submit, by choosing one of six possible strategies. They do not know about advice part until finishing the experiment.

Following previous literature on advice (Schotter, 2003; Schotter and Sopher, 2007), these subjects will be paid $20 \%$ of the average group earning of their laboratory successors who read their advice, so that they will have the incentive to give sincere advice. Subjects are also free to give no advice, and are paid the same as those who give advice. At the end of the experiment, subjects are paid their earnings for playing the matching game in that session immediately. They are told that they will be contacted via e-mail and are given a second payment based on the average group earning of their successors. This second payment was handed out to subjects after all sessions are finished. Therefore, the data in the baseline treatment serves two purposes: they are used to construct advice and historical information for the other two treatments, as well as serving as a benchmark against which individual behaviors and the performance of the mechanism in the other two treatments can be compared.

To test whether subjects are more likely to adopt truth-telling when learning from their predecessors, I then conduct two other treatments: the advice treatment and the observation treatment. In the advice treatment, subjects play the same game as that in the baseline treatment, except that they are given advice from subjects in the baseline treatments at the beginning of the experiment. The advice is given in the form of common knowledge. The histograms of suggested strategies for each of three types are written on the instruction and are also read aloud by the experimenter. Hence each subject not only knows all the advice given to each type of subjects, but each of them also knows that other subjects are looking at the same pieces of advice in a sheet of paper, and everyone knows that each of them knows that other subjects are looking at the same pieces of advice, and so on. I choose the common knowledge of advice as it has proven to be a good coordination device, such as significantly increasing contribution level in public goods game (Chaudhuri et al. 2006), or coordinating on the Pareto efficient outcome in minimum effort game (Chaudhuri et al. 2009), etc. Therefore, common knowledge is expected to help subjects coordinate on one Nash equilibrium in this matching game.

The observation treatment is designed to be compared with the advice treatment. In this treatment, instead of reading advice given by participants in the baseline treatment, subjects are provided with a piece of paper, which contains all the strategies played by each type of subjects and the average payoff for playing that strategy in each of the 15 periods in the baseline treatment. 
Therefore, by mapping from empirical strategies into actual payoffs, subjects may have an idea about what they are expected to earn when using different strategies. It is then interesting to check whether subjects are more likely to submit their true preferences in the observation treatment compared to the baseline treatment. Moreover, I would like to see whether the truth-telling rate in the advice treatment is as high as that in the observation treatment, as the former treatment can be easily implemented in the real-life matching market.

\subsection{Experimental Procedure}

In each experimental session, each subject is randomly assigned an ID number and is seated in front of the corresponding terminal in the laboratory. The experimenter reads the instructions aloud. Subjects ask questions, which are answered in private. I check subjects' understanding by asking them to answer the incentivized review questions at their own pace. After everyone finishes the review questions, the experimenter distributes the answers and goes over the answers in public. Afterwards, subjects go through 15 periods of matching experiment. In each period, each subject is asked to submit a full ranking of objects. After all rankings are submitted, the server allocates the objects according to the Deferred Acceptance mechanism and informs each subject of their allocated object and respective payoff. At the end, each subject fills out a demographics and strategy survey on the computer. Each subject is paid in private at the end of the experiment. Each session lasts approximately 90 minutes. The first 40 minutes are used for instruction. The experiment is programmed in z-Tree (Fischbacher, 2007).

Table 4: Features of Experimental Sessions

\begin{tabular}{ccccc}
\hline \hline Environment & Treatment & \#Subjects per session & \#Session & Total \# of subjects \\
\hline \multirow{3}{*}{ Uncorrelated Preference } & Baseline & 12 & 3 & 36 \\
\cline { 2 - 5 } & Advice & 12 & 3 & 36 \\
\cline { 2 - 5 } Correlated Preference & Observation & 12 & 3 & 36 \\
\cline { 2 - 5 } & Baseline & 12 & 3 & 36 \\
\cline { 2 - 5 } & Advice & 12 & 3 & 36 \\
\cline { 2 - 5 } & Observation & 12 & 3 & 36 \\
\hline \hline
\end{tabular}

Table 4 summarizes the features of experimental sessions. Three independent sessions are conducted for each treatment, with twelve subjects recruited in each session. All sessions are conducted in French at GATE-LAB, the Experiment Economics Laboratory in Lyon in October 2014 and February 2015. The subjects are mainly students from Ecole Central engineering school and EM Lyon business school. No one participated more than once. This gives us a total of 18 independent sessions. In total, 216 subjects have participated in the experiment. The exchange rate is 20 experiment points for 1 Euro for all sessions. Each subject also receives a participation fee of 
3 Euros. The average earning (including participation fee) is 18.7 Euros. The English translations of the experimental instructions can be found in Appendix A.

\subsection{Hypothesis}

In the uncorrelated preference environment, the game induced by the Deferred Acceptance mechanism has two Pareto ranked Nash equilibrium outcomes, which are also stable outcomes. The Pareto efficient stable matching outcome $\mu_{u}^{S}$ is the following, with an aggregate payoff of 600:

$$
\mu_{u}^{S}=\left(\begin{array}{lll}
1 & 2 & 3 \\
A & B & C
\end{array}\right)
$$

With Pareto efficient stable outcome, each type of subjects can obtain their most preferred objects. Correspondingly, the Nash equilibrium strategy profiles that sustain this Pareto efficient outcome are the following: $\left(P_{1}: A, \times, \times, P_{2}: B, \times, \times, P_{3}: C, \times, \times\right)$. That is, only if all types of subjects report their true top choices, they can coordinate on Pareto efficient stable outcome.

The other Nash equilibrium outcome $\mu_{u}^{O}$ is Pareto inferior stable matching, with an aggregate payoff of 360 :

$$
\mu_{u}^{O}=\left(\begin{array}{lll}
1 & 2 & 3 \\
B & C & A
\end{array}\right)
$$

That is, each type of subjects obtain their second most preferred objects in matching $\mu_{u}^{O}$. Strategy profiles: $\left(P_{1}: B, \times, \times, P_{2}: \times, \times, \times, P_{3}: \times, \times, \times\right)$, except $\left(P_{1}: B, \times, \times, P_{2}: A, \times, \times, P_{3}\right.$ : $C, \times, \times)$, and $\left(P_{1}: \times, \times, \times, P_{2}: C, \times, \times, P_{3}: \times, \times, \times\right)$, except $\left(P_{1}: A, \times, \times, P_{2}: C, \times, \times, P_{3}:\right.$ $B, \times, \times)$, and $\left(P_{1}: \times, \times, \times, P_{2}: \times, \times, \times, P_{3}: A, \times, \times\right)$, except $\left(P_{1}: C, \times, \times, P_{2}: B, \times, \times, P_{3}:\right.$ $A, \times, \times)$ will lead to this Pareto inferior stable matching 10 That is, any subject can only obtain his second preferred object by playing safety choice bias.

There are also two Nash equilibrium outcomes in the correlated preference environment. One is stable, and the other one is Pareto efficient but unstable. The stable matching outcome $\mu_{c}^{S}$ is the following, with an aggregate payoff of 360:

$$
\mu_{c}^{S}=\left(\begin{array}{lll}
1 & 2 & 3 \\
B & C & A
\end{array}\right)
$$

With stable outcome, each type of subjects obtain their second preferred objects. Correspondingly, the Nash equilibrium strategy profiles that sustain this stable outcome are: $\left(P_{1}\right.$ :

\footnotetext{
${ }^{10}\left(P_{1}: A, \times, \times, P_{2}: C, \times, \times, P_{3}: B, \times, \times\right)$ and the other two exceptions will not lead to any Nash equilibrium. Note that any one is guaranteed to obtain his second preferred object if he reports it as first choice, no matter what others will play.
} 
$\left.A, B, C(B, \times, \times), P_{2}: A, C, B(C, \times, \times), P_{3}: B, A, C(A, \times, \times)\right)$ except $\left(P_{1}: A, B, C, P_{2}:\right.$ $\left.C, \times, \times, P_{3}: B, A, C\right)$. That is, each subject can only obtain their second preferred object if everyone plays truthfully. A given subject also obtains his second preferred object by playing safety choice bias.

In fact, strategy profiles $\left(P_{1}: A, B, C, P_{2}: C, \times, \times, P_{3}: B, A, C\right)$ lead to the other Nash equilibrium outcome $\mu_{c}^{E}$, which is unstable but Pareto efficient, with an aggregate payoff of 520:

$$
\mu_{c}^{E}=\left(\begin{array}{ccc}
1 & 2 & 3 \\
A & C & B
\end{array}\right)
$$

This Pareto efficient outcome can be achieved if subject of Type 2 misrepresents his preference by playing safety choice bias when subjects of Type 1 and Type3 reveal their preferences truthfully. Therefore, Type2's misrepresentation benefits the other two players in a way to help them obtain their most preferred objects without hurting himself. However, this outcome is unstable, because Type 2 prefers object $A$ to $C$, and also has higher priority than Type 1 for $A$.

Next I will derive experimental hypotheses. From theoretical prediction Theorem 2, truthtelling is a weakly dominant strategy for subjects on the proposing side under the Deferred Acceptance mechanism. In both environments of our specific experiment, a particular subject is guaranteed with his second preferred object, and sometimes can obtain most preferred object by playing truthfully $[1$ This leads to the general null hypothesis in this experiment.

Hypothesis 1 (Null Hypothesis). There is no difference in the proportion of truthfully preference revelation in all three treatments of either environment. Hence, there is no difference in the proportion of stable outcome in all three treatments of either environment.

The construction of alternative hypotheses starts from general experimental observation that not all subjects reveal their preference truthfully (see e.g., Chen and Sönmez (2006); Chen and Kesten (2014); Echenique et al. (2014)). Subjects in the lab are boundedly rational and some of them are confused due to the complexity of the mechanism or the non-transparency of the dominant strategy. These confused subjects thus probably think it is risky to report true top choices and play safety choice bias instead. Moreover, there are multiple Nash equilibria in our particular environments. Subjects probably stick to one Nash equilibrium strategy, which is not necessarily truth-telling. Therefore, a certain fraction of subjects are expected not to reveal their true preferences in the first period of baseline treatment.

Previous laboratory experiments show that people learn to play truthfully under the Deferred Acceptance mechanism after repeating the matching game for several times (Featherstone and Niederle, 2014; Chen and Kesten, 2014). In this experiment, participants will play the simple

\footnotetext{
${ }^{11}$ Subjects of Type 2 in the correlated preference environment can only obtain their second preferred objects by playing truthfully.
} 
game for 15 periods, and learn their own allocated objects and respective payoffs in each period. With ample experience and observations, subjects are expected to learn that truth-telling is the best strategy in the end ${ }^{12}$. Moreover, previous literature on advice indicates that subjects are expected to give sincere advice about the best strategies if their payments are aligned with their successors', 13 which is expected to be truth-telling in our setting.

Meanwhile, as subjects are paid on the average group earning of their laboratory successors, they have both social motivation and monetary incentive to advise strategies that can encourage successors to coordinate on social optimal outcome. That is, subjects in the uncorrelated preference environment should advise on truth-telling behaviors in order to coordinate on the Pareto efficient stable outcome. On the other hand, to achieve Pareto efficient outcome, subjects of Type1 and Type 3 in the correlated preference environment should advise on truth-telling, and subjects of Type 2 will suggest on safety choice bias. However, as subjects can only observe their own payoffs at the end of each period, it is more difficult for subjects in the correlated preference environment to realize how to coordinate on social optimal outcome.

Furthermore, previous literature on advice has shown that people tend to follow advice given by their peers who have experienced the game, which is expected to be truth-telling in this setting (see e.g., Schotter and Sopher (2003, 2006, 2007); Brandts et al.). Therefore, subjects in the advice treatment are expected to follow advice and play truthfully. Meanwhile, in the uncorrelated preference environment, if it is a common knowledge that the majority advice is on truth-telling, subjects may believe that others in their groups are more likely to play truthfully, and thus would like to coordinate on truth-telling as well.

There are two Pareto ranked Nash equilibrium outcomes in the uncorrelated preference environment, and the Pareto efficient stable outcome can only be reached if every subject ranks their most preferred object first. Any strategic behavior in the sense of listing the true top choice into a lower position will result in a sub-optimal outcome. Hence, there is a positive correlation between truth-telling and the probability of reaching Pareto efficient stable outcome in the uncorrelated preference environment. On the other hand, truth-telling and safety bias choice can lead to the same stable outcome in the correlated preference environment. The Pareto efficient but unstable outcome can only be achieved when Type 2 misrepresents his preference and other types play truthfully, which is hard to coordinate on.

In the observation treatment, as subjects observe all strategies played by their predecessors and the average payoff for playing each strategy, they will have an empirical link between the submitted strategies and actual payoffs. The positive correlation between truth-telling and payoff

\footnotetext{
${ }^{12}$ Subjects of Type 2 in the correlated preference environment have same payoffs by playing safety choice as truthtelling. It is thus interesting to see whether subjects of Type 2 are more likely to play truthfully and advice on truthtelling as well.

13 Schotter (2003) has a comprehensive survey on naïve advice.
} 
is more transparent in the uncorrelated preference environment, but this link is relatively weak in the correlated preference environment. Thus, subjects are more likely to play truthfully when observing behaviors and respective payoffs in the uncorrelated preference environment, compared to that in the correlated preference environment.

Hence, I propose the following two alternative hypotheses:

Hypothesis 2 (Alternative Hypothesis 1). The proportion of truth-telling in the advice treatment and in the observation treatment is greater than that in the baseline treatment in the uncorrelated preference environment.

Hypothesis 3 (Alternative Hypothesis 2). The probability of obtaining Pareto efficient stable outcome $\mu_{u}^{S}$ relative to Pareto inferior stable outcome $\mu_{u}^{O}$ and other unstable outcomes is greater in the advice treatment and in the observation treatment than that in the baseline treatment in the uncorrelated preference environment.

\section{Results}

In this section, I mainly present results of individual behaviors and the performances of the mechanism (i.e., first choice accommodation, stability and efficiency) in the three treatments of the two environments, respectively. In presenting the results, some shorthand notations are introduced. The baseline treatment, the advice treatment and the observation treatment are referred to as Base, Ad., and Ob. in this section, respectively. Let $x>y(x<y)$ denote that a measure in one treatment $x$ is greater (less) than the corresponding measure in treatment $y$ at the $5 \%$ significance level or less. Let $x \sim y$ denote that a measure in treatment $x$ is not significantly different from the corresponding measure in treatment $y$ at the $5 \%$ significance level.

For individual behaviors, I would like to see the extent to which individuals reveal their preferences truthfully in the three treatments, with particular attention to whether truth-telling rates are higher in the advice and observation treatments than that in the baseline treatment in each environment. Moreover, when there is misrepresentation, it is interesting to know whether individuals play safety choice bias. As most players usually participate once in real-life matching market, I will mainly focus on behaviors in the first period.

To simplify the description of strategies, I will make use of the notation $(1,2,3)$ for the submitted preference list where a subject ranks his most preferred object first, his second preferred object second, and his least preferred object last. The other five strategies $(1,3,2),(2,1,3),(2,3,1)$, $(3,1,2)$, and $(3,2,1)$ have similar interpretations.

Truth-telling means that entire reported ranking is identical to the subject's true preference ranking, which is the notation $(1,2,3)$ in this experiment. $(1,3,2)$ is defined as behavior of "skip- 
ping second choice", that is, subjects misrepresent their preferences by skipping their second preferred objects. The notation $(2, \times, \times)$ is "safety choice bias". Likewise, the notation $(3, \times, \times)$ is defined as "irrational behavior".

\subsection{Uncorrelated Preference Environment}

\subsubsection{Individual Behavior}

Upper-left panel (upper-right panel) in Figure 1 present the proportion of truth-telling (safety choice bias) over time for each of three treatments in the uncorrelated preference environment. Likewise, other misrepresentation patterns including skipping second choice and irrational behavior are presented in lower panels of Figure 1 .
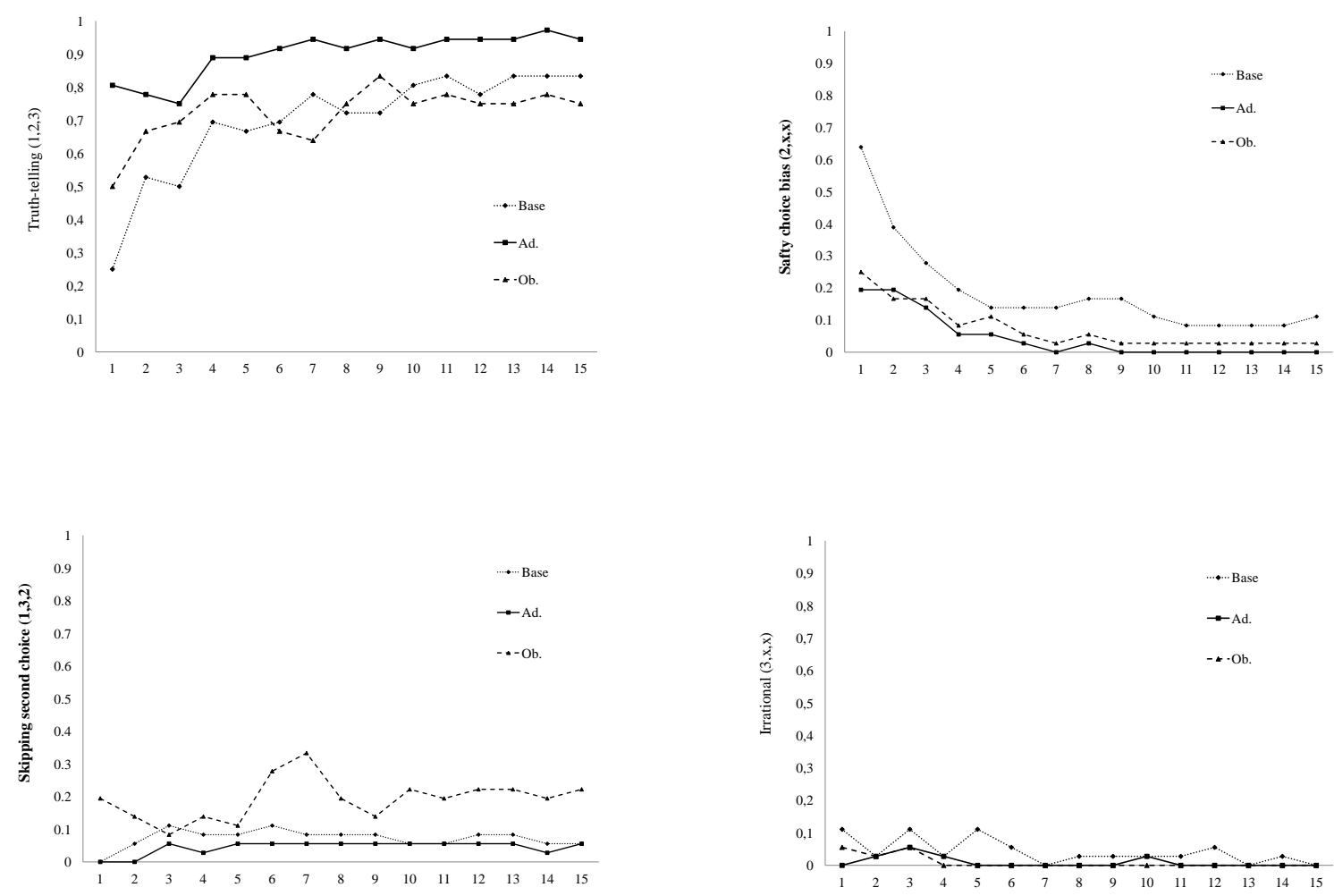

Figure 1: Uncorrelated Preference: Empirical Distributions of Submitted Rankings across Treatments

It can be seen from Figure 1 that the most salient behavior is truth-telling for all three treatments in the uncorrelated preference environment. The ranking of treatments in the truth-telling follows 
the order of Ad. $>$ Ob. $>$ Base. The proportion of truthful preference revelation is as low as $25 \%$ in the first period of the baseline treatment, nevertheless, it has increased greatly since second period. In contrast, the proportion of truthful preference revelation in the advice treatment is as high as $80.6 \%$ and is $50 \%$ in the observation treatment since the first period. Furthermore, if subjects do not reveal true preferences, they usually play safety choice bias, in which the ranking of three treatments follows the order of Base $>$ Ob. $\sim$ Ad.. The proportion of safety choice bias is as high as $63.3 \%$ in the first period of the baseline treatment, but dropping rapidly after several periods. In addition, there are also some participants skipping second preferred objects, which is especially popular in the observation treatment. Next, I will focus on results of truthful preference revelation and safety choice bias.

Table 5: Uncorrelated Preference: Truth-telling and Safety choice bias

\begin{tabular}{|c|c|c|c|c|c|c|}
\hline & \multicolumn{3}{|c|}{ Truth-telling } & \multicolumn{3}{|c|}{ Safety Choice Bias } \\
\hline First period & Proportion & $H_{a}$ & $P$-value & Proportion & $H_{a}$ & $P$-value \\
\hline Base & 0.250 & Base $<$ Ad. & 0.000 & 0.639 & Base $>$ Ad. & 0.000 \\
\hline Ad. & 0.806 & Base $<$ Ob. & 0.014 & 0.194 & Base $>$ Ob. & 0.000 \\
\hline Ob. & 0.500 & Ob. $<$ Ad. & 0.003 & 0.250 & Ob. $>$ Ad. & 0.285 \\
\hline
\end{tabular}

Notes. First period: one-sided proportion of t-tests using individuals as observations.

Table 6: Truth-telling and Safety Choice Bias: Probit Regressions

\begin{tabular}{|c|c|c|c|c|c|c|}
\hline & & Truth-tellin & & & ety Choice 1 & \\
\hline & (1) & (2) & (3) & (4) & (5) & (6) \\
\hline Ad. & $0.218 * * *$ & $0.254 * * *$ & $0.260 * * *$ & $-0.139 * * *$ & -0.049 & $-0.064 *$ \\
\hline & $(0.076)$ & $(0.044)$ & $(0.045)$ & $(0.037)$ & $(0.037)$ & $(0.039)$ \\
\hline $\mathrm{Ob}$. & 0.019 & $0.143 * *$ & $0.144 * *$ & $-0.094 * *$ & $-0.090 * * *$ & $-0.093 * * *$ \\
\hline & $(0.062)$ & $(0.060)$ & $(0.062)$ & $(0.040)$ & $(0.022)$ & $(0.022)$ \\
\hline Period & $0.018 * * *$ & $0.025 * * *$ & $0.022 * * *$ & $-0.017 * * *$ & $-0.015 * * *$ & $-0.013 * * *$ \\
\hline & $(0.003)$ & $(0.004)$ & $(0.004)$ & $(0.002)$ & $(0.003)$ & $(0.003)$ \\
\hline Ad. $\times$ Period & & -0.005 & -0.006 & & $-0.021 * *$ & $-0.016^{*}$ \\
\hline & & $(0.010)$ & $(0.009)$ & & $(0.010)$ & $(0.010)$ \\
\hline Ob. $\times$ Period & & $-0.016 * * *$ & $-0.016^{* * *}$ & & -0.000 & 0.000 \\
\hline & & $(0.005)$ & $(0.005)$ & & $(0.008)$ & (0.008) \\
\hline Period 1 & & & $-0.121 * * *$ & & & $0.061 *$ \\
\hline & & & $(0.040)$ & & & $(0.035)$ \\
\hline
\end{tabular}

\begin{tabular}{lllllll}
\hline Observations & 1,620 & 1,620 & 1,620 & 1,620 & 1,620 & 1,620 \\
\hline \hline
\end{tabular}

Notes. Standard errors in parentheses are clustered at the session. Coefficients are marginal effects. $* * * \mathrm{p}<0.01, * * \mathrm{p}<0.05, * \mathrm{p}<0.1$. 
Result 1 (Uncorrelated Preference: Truthful Preference Revelation). The proportion of truthful preference revelation in the baseline treatment is significantly lower than that in either advice treatment or observation treatment.

Support. Table 5 presents the proportions of truthful preference revelation, as well as the proportions of safety choice bias for the first period. $P$-values are computed from one-sided proportion of t-tests using individuals as independent observations. I also conduct six probit regressions investigating treatment effect on the likelihood of playing truthfully and playing safety choice bias. The results are summarized in Table 6 . The dependent variable is truth-telling in specifications (1) through (3), and safety choice bias in specifications (4) through (6). The independent variables include (omitted variables in parentheses): Ad., Ob., (Base), Period, Ad. $\times$ Period, Ob. $\times$ Period, Period 1, which indicate dummy variables "advice treatment" and "observation treatment", "period" variable, interaction term between "advice treatment" and "period", interaction term between "observation treatment" and "period", and dummy variable "Period 1" which is equal to one if it is the first period. In each specification, standard errors are clustered at the session level.

In the first period, only $25 \%$ of participants reveal their true preferences in the baseline treatment, while $80.6 \%$ and $50 \%$ of participants play truthfully in the advice treatment and in the observation treatment, respectively. One-sided $t$-tests of proportions with the null hypothesis of equal proportion are rejected in favor of $H_{a}$ : Base $<$ Ad. and $H_{a}$ : Base $<$ Ob., with $p$-values $<0.014$. Meanwhile, a $t$-test of proportions with the null hypothesis of equal proportion is rejected in favor of $H_{a}$ : Ob. < Ad., with $p$-value $=0.003$. Over all periods, on average, $69.8 \%$ of participants reveal their true preferences in the baseline treatment, while $90 \%$ and $72.4 \%$ of participants play truthfully in the advice treatment and in the observation treatment, respectively. In specification (3) of Table 6, the coefficients of Advice and Observation are positive and significant, indicating that truth-telling rate is $26 \%$ (14\%) higher when having adivce or observing histories compared to that in the baseline treatment.

By Result 1 , we can reject null in favor of Hypothesis 2 that subjects are more likely to reveal their true preferences in the advice treatment and in the observation treatment than those in the baseline treatment in the uncorrelated preference environment. The result indicates that whereas a large number of subjects fail to play truthfully at the beginning without prior experience of their own or from peers, advice and history from previous players can greatly encourage them to coordinate on truth-telling behavior. For the high truth-telling rate in the observation treatment, one plausible reason is that subjects have a clear link between behaviors and respective earnings based on empirical data of their predecessors, therefore are more easily to realize best strategies. It is also interesting to see that subjects are significantly more likely to play truthfully when having advice than when observing histories of advisors. 
I now explore misrepresentation behavior in the experiment. Due to our specific design, subjects have the highest priority for their second preferred objects. Whatever their opponents play, subjects are guaranteed their second preferred objects if ranking them first. On the other hand, truthful preference revelation makes subjects at least obtaining their second preferred objects (i.e., dominant strategy), but subjects have the lowest priority for their most preferred objects. Therefore, if subjects do not figure out dominant strategy and wrongly perceive that reporting true top choice is risky, they are likely to play safety choice bias by submitting their second preferred objects as first choices. It can be seen from Figure 1 that safety choice bias is a prevalent behavior if subjects do not reveal their true preferences. This percent is as high as $63.9 \%$ in the first period of the baseline treatment. In comparison, subjects are less likely to play safety choice bias in the advice treatment and in the observation treatment than those in the baseline treatment.

Result 2 (Uncorrelated Preference: Safety Choice Bias). The proportion of safety choice bias in the baseline treatment is significantly higher than that in the advice treatment or in the observation treatment.

Support. In the first period, $63.9 \%$ of participants misrepresent their preferences in a way of safety choice bias in the baseline treatment, while only $19.4 \%$ and $25 \%$ of participants play safety choice bias in the advice treatment and in the observation treatment, respectively. One-sided $t$ tests of proportions with the null hypothesis of equal proportion are rejected in favor of $H_{a}$ : Base $>$ Ad. and $H_{a}$ : Base $>$ Ob., with $p$-values $=0.000$. Meanwhile, a $t$-test of proportions has $p$-value $=0.285$, from which we cannot reject the null hypothesis of equal proportion for Ad. and Ob. Over all periods, on average, $18.7 \%$ of participants have safety choice bias in the baseline treatment, while only $4.6 \%$ and $7.4 \%$ of participants misrepresent their preferences in the advice treatment and in the observation treatment, respectively. In specification (4) of Table 6, the coefficients of Advice and Observation are positive and significant, indicating that the proportion of safety choice bias is $13 \%$ (9\%) lower when having adivce or observing histories compared to that in the baseline treatment.

\subsubsection{Advice}

It has been seen that participants are significantly more likely to reveal their true preferences in the advice treatment compared to the baseline treatment in the uncorrelated preference environment. It thus interesting to ask whether this increase in truth-telling is due to advice. In order to answer this question, I would like to check: (1) whether participants learn that truth-telling is the best strategy after repeating the game for ample periods; (2) whether participants would like to give advice on truth-telling to their successors; (3) whether participants in the advice treatment would like to accept advice given by their predecessors. 
It can be seen from Table 6 that there is a significant learning effect for all three treatments. The coefficient of variable Period 1 in specification $(3)$ is $-0.121(p<0.01)$, indicating that the proportion of truth-telling increases by $12 \%$ staring second period. In specifications (1) through (3) of Table 6, period effect indicated by the coefficients of Period is 0.018 ( $p<0.01) 0.025$ $(p<0.01)$ and $0.022(p<0.01)$, indicating that the proportion of truth-telling increases by about $2 \%$ per period in the baseline treatment. We also find that, coefficients of variable Ob. $\times$ Period in specification (2) and (3) are negative and significant, indicating period effect is smaller in the observation treatment than that in the other two treatments. Similarly, in specification (4) through (6) of Table 6, the coefficients of Period are significant and negative, indicating that the proportion of safety choice bias decreases by $1.5 \%$ per period.

In addition, in order to check whether subjects would like to stick with truth-telling or switch their behaviors, I compute the proportion of subjects who always play truthfully since that period, which is presented in Figure 2. Compared with the proportion of truthful preference revelation in Figure 1, we can see that in the first few periods, subjects would like to try different strategies, switching between truthful and non-truthful behaviors. However, when time goes on, more and more subjects tend to stick with truth-telling, and this proportion has stabilized in last five periods.

All these results indicate that subjects tend to play truthfully when repeatedly participating in the experiment, especially after experiencing the first period. The learning effect is particularly obvious in the baseline treatment, with truth-telling rate increasing from $25 \%$ in the first period to over $80 \%$ in last five periods. Therefore, the majority of subjects have learned to play truthfully in the end.

It is then interesting to know whether subjects would like to advise what they have learned to their successors, especially whether they will suggest on truth-telling behavior. Table 7 presents the histogram of strategies that participants in the baseline treatment advise to play. The majority of participants, which is $83.3 \%$, advise successors of their own types to submit their truthful preferences, namely strategy $(1,2,3)$. There are also $5.6 \%$ and $8.3 \%$ of participants suggesting to play strategies $(1,3,2)$ and $(2,1,3)$, respectively, which are behaviors of skipping second choice and safety choice bias. Interestingly, the distribution of advised strategies is in line with what advisors have played in last period, that is, $83.3 \%, 5.6 \%$ and $8.3 \%$ of advisors indeed play strategies $(1,2,3),(1,3,2)$ and $(2,1,3)$ in the last period, respectively. Only $2.8 \%$ of participants (one participant) who play strategy $(2,3,1)$ in the last period advise on strategy $(3,2,1)$ instead.

In order to check whether participants give advice based on their behaviors, I further calculate distributions of advice conditional on last-period behaviors. It can be seen from Table 8 that most of the time, subjects advise what they have played. For example, among subjects who submit their true preferences, $100 \%$ of them advise their successors to play truthfully. All subjects who played the strategy $(2,1,3)$ also advise on the same strategy $(2,1,3)$. Note that, there are no participant 


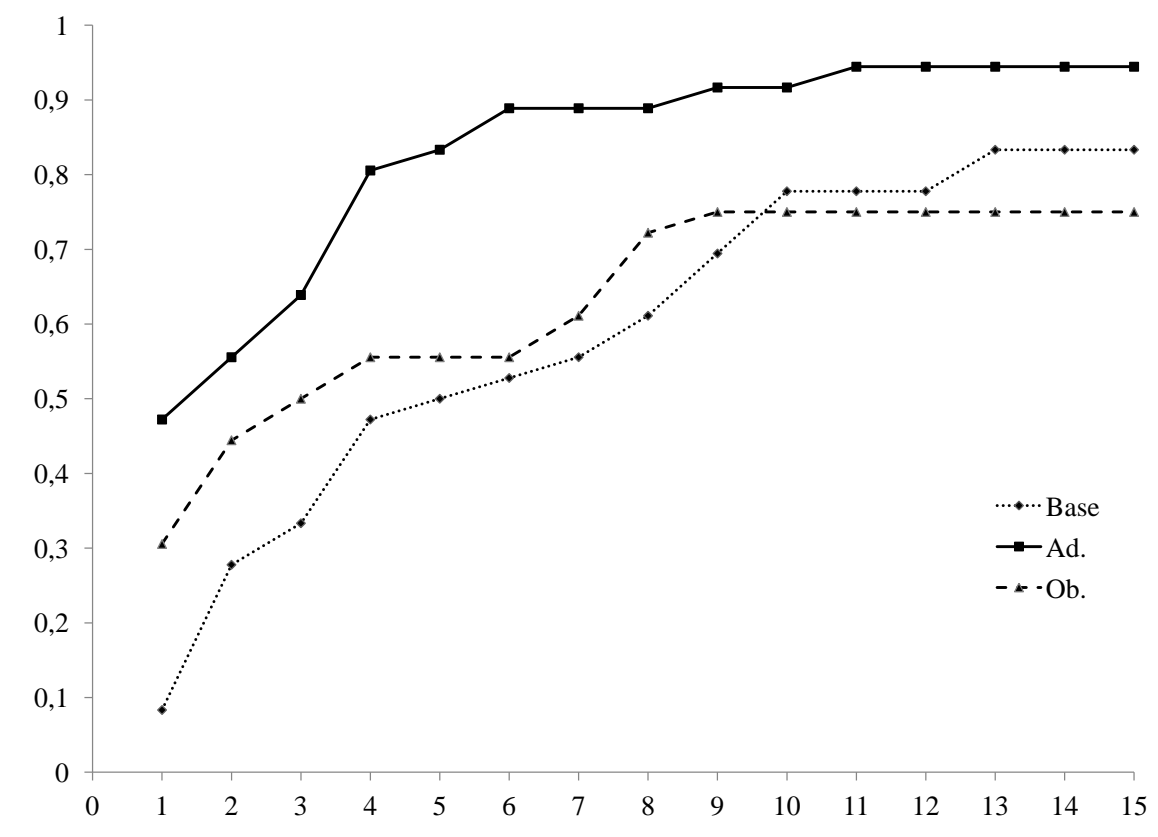

Figure 2: Uncorrelated Preference: Proportion of Subjects Who Always Play Truthfully Since that Period 
playing strategies $(3,1,2)$ and $(3,2,1)$ in the last period, so there is no given advice conditional on these two strategies. Results indicate that subjects would like to transmit what they have learned to their successors. Moreover, the majority of subjects learn to play truthfully with ample repetition in the baseline treatment, and would like to advise their successors to submit their true preferences, which is the best strategy in this experiment.

Table 7: Uncorrelated Preference: Empirical Distributions of Behaviors and Advice in the Baseline and Advice Treatments

\begin{tabular}{lcccccc}
\hline Baseline treatment: & $(1,2,3)$ & $(1,3,2)$ & $(2,1,3)$ & $(2,3,1)$ & $(3,1,2)$ & $(3,2,1)$ \\
\hline Behavior in last 5 periods & 0,822 & 0,067 & 0,072 & 0,017 & 0,022 & 0,000 \\
Behavior in last period & 0,833 & 0,056 & 0,083 & 0,028 & 0,000 & 0,000 \\
Given Advice & 0,833 & 0,056 & 0,083 & 0,000 & 0,028 & 0,000 \\
\hline Advice treatment: & $(1,2,3)$ & $(1,3,2)$ & $(2,1,3)$ & $(2,3,1)$ & $(3,1,2)$ & $(3,2,1)$ \\
\hline Behavior in first period & 0,806 & 0,000 & 0,167 & 0,028 & 0,000 & 0,000 \\
Behavior in first 5 periods & 0,822 & 0,028 & 0,011 & 0,042 & 0,025 & 0,017 \\
\hline \hline
\end{tabular}

Table 8: Uncorrelated Preference: Distributions of Advice Conditional on Behaviors in Last Period

\begin{tabular}{ccccccc}
\hline \hline Behavior\Advice & $(1,2,3)$ & $(1,3,2)$ & $(2,1,3)$ & $(2,3,1)$ & $(3,1,2)$ & $(3,2,1)$ \\
\hline$(1,2,3)$ & 1 & 0 & 0 & 0 & 0 & 0 \\
$(1,3,2)$ & 0 & 1 & 0 & 0 & 0 & 0 \\
$(2,1,3)$ & 0 & 0 & 1 & 0 & 0 & 0 \\
$(2,3,1)$ & 0 & 0 & 0 & 0 & 1 & 0 \\
$(3,1,2)$ & 0 & 0 & 0 & 0 & 0 & 0 \\
$(3,2,1)$ & 0 & 0 & 0 & 0 & 0 & 0 \\
\hline \hline
\end{tabular}

Subjects also would like to take advice given to them. By viewing histograms of strategies that predecessors advise to play, subjects in the advice treatment learn that the majority of advice is on truth-telling behavior. Accordingly, $80.6 \%$ of subjects decide to submit their true preferences in the first period. In contrast, when there is no advice, the proportion of truthful preference revelation in the first period is only $25 \%$ in the baseline treatment and is $50 \%$ in the observation treatment. Given advice, subjects who do not play truthfully at the beginning also would like to transfer to truth-telling in later periods (see Figure 2). Moreover, no subject plays irrational behavior in the first period when having advice. Results from Table 6 also indicate that, even when controlling for learning, the proportion of truth-telling in the advice treatment is $25 \%(11 \%)$ significantly higher than that in the baseline treatment (observation treatment) when there is no advice. Since each subject observes all given advice, it is not possible to examine the effect of different advice on individual behavior. I thus use Kolmogorov-Smirnov test to check for equal distributions of advised strategies and first-period behaviors in the advice treatment, and find no statistically significant difference $(p$ value $=1.000)$. However, there are significant differences on 
the distributions of advised strategies and first-period behaviors in the baseline treatment ( $p$ value $=0.000)$ as well as in the observation treatment ( $p$ value $=0.037$ )

To examine how advice improves subject's decision making and why a significantly higher truth-telling rate persists with advice, I calculate subjects' respective payoffs for playing truthfully and non truthfully in the advice treatment. In the first period, among those who submit truthful preferences, $51.7 \%$ of subjects obtain their most preferred objects, and $48.3 \%$ of them obtain their second preferred objects. Therefore, the average earning for playing truthfully in the first period is 161.4 points. On the other hand, for subjects who do not play truthfully in the first period, all of them obtain their second preferred objects, and the average earning is 120 points accordingly. When more subjects coordinate on truth-telling behavior in later periods, the average earning for playing truthfully increases as well. Overall, on average, 93\% of subjects obtain their most preferred objects because of ranking them as first choices, and the average earning is 194.4 points. In contrast, subjects earn 120 points for playing safety choice and 40 points for irrational behavior. This substantial payoff difference with different strategies provides partial justification why subjects would like to accept advice of truth-telling and why they will stick with truth-telling behavior afterward.

There are also many reasons why subjects would like to accept advice. This is probably because real players are used to listen to advice from others, such as parents, teachers, friends, colleagues, etc., or because subjects think the advice is valuable, which is especially reasonable as the advisor's payment in our experiment is aligned with their successors. It has also been documented by literature on advice that subjects tend to follow advice because both the processes of giving advice and deciding whether to follow advice force subjects to learn better. Therefore, subjects in our experiment may think differently when receiving advice, and this process increases rationality of our subjects. On the other hand, the game employed in the experiment is a highly coordinated one, where Pareto efficient outcome can only be achieved if everyone reports his true top choice. As the majority of advice is on truth-telling behavior, which is publicly announced in the form of common knowledge, subjects will believe their opponents are more likely to play truthfully, therefore, they also would like to coordinate on truth-telling behavior. As a result, the large number of subjects play truthfully due to advice, the higher earnings they are paid for. This positive feedback further encourages more subjects to adopt truth-telling in later periods.

\subsubsection{First Choice Accommodation}

In this section, I will examine treatment effects on three measures of aggregate performance: first choice accommodation, stability and efficiency. I first look at the actual outcome distribution realized in the lab. As subjects have ordinal preferences in matching game, it is interesting to have a first look at how many subjects obtain their most preferred objects, their second preferred ob- 
jects and least preferred objects, instead of directly comparing average payoffs. The proportion of subjects obtaining their most preferred object thus refers to first choice accommodation. In our experiment environment, all subjects should obtain their most preferred objects when everyone plays truthfully. Therefore, theory predicts that the proportion of first choice accommodation should be equal to 1 . Then the actual outcome distribution with submitted preferences can be compared to this truth-telling counterfact to evaluate the effectiveness of the mechanism.

Figure 3 presents the cumulative distributions of actual outcomes for each of three treatments. It is seen from Figure 3 that only half of subjects obtain their first choices in the baseline treatment. On the contrary, a large fraction of subjects in the advice treatment and in the observation treatment are accommodated to their true first choices. The ranking of treatments in the proportion of subjects obtaining their true top choices follows the order of Ad. $\sim$ Ob. $>$ Base. Moreover, most of subjects at least obtain their second preferred objects in all three treatments. Next, I will focus on first choice accommodation as it is interested by policy makers in the field.

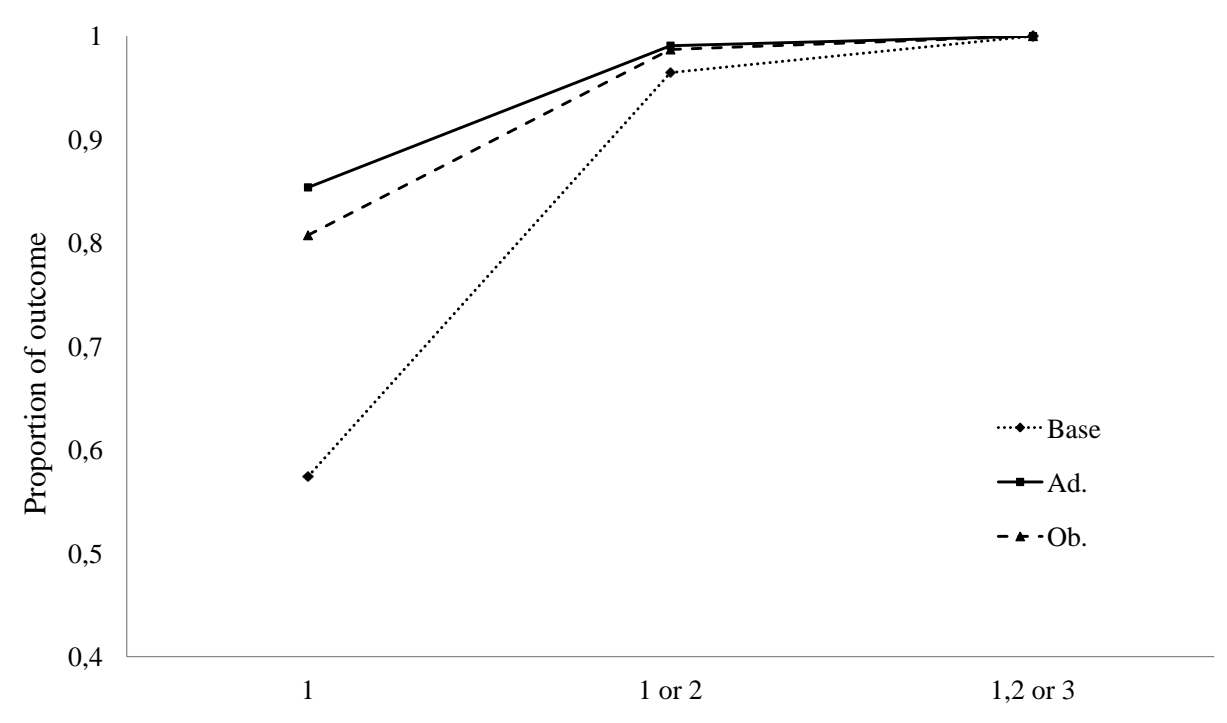

Figure 3: Uncorrelated Preference: CDFs of True Choice Accommodation with Submitted Preferences

Result 3 (Uncorrelated Preference: First-choice accommodation). The proportions of first choice accommodation in the advice treatment and the observation treatment are significantly higher than 
Table 9: Uncorrelated Preference: Proportions of First Choice Accommodation and Stable Outcomes

\begin{tabular}{|c|c|c|c|c|c|c|c|}
\hline \multirow[b]{2}{*}{ First period } & \multicolumn{2}{|c|}{ 1st Choice Accom. } & \multicolumn{4}{|c|}{ Stable Outcomes } & \multirow[b]{2}{*}{$H_{a}$} \\
\hline & Proportion & $P$-value & Optimal & Inferior & Proportion & $P$-value & \\
\hline Base & 0,111 & 0,002 & 0,083 & 0,833 & 0,917 & 0,159 & Base $<$ Ad. \\
\hline Ad. & 0,417 & 0,002 & 0,417 & 0,583 & 1,000 & 0,142 & Base $<$ Ob. \\
\hline $\mathrm{Ob}$. & 0,417 & 0,500 & 0,333 & 0,417 & 0,750 & 0,035 & Ob. < Ad. \\
\hline \multicolumn{8}{|l|}{ All Periods } \\
\hline Base & 0,574 & 0,040 & 0,539 & 0,356 & 0,894 & 0,040 & Base $<$ Ad. \\
\hline Ad. & 0,854 & 0,100 & 0,844 & 0,128 & 0,972 & 0,040 & Base $<$ Ob. \\
\hline $\mathrm{Ob}$. & 0,807 & 0,450 & 0,794 & 0,167 & 0,961 & 0,210 & Ob. $<$ Ad. \\
\hline
\end{tabular}

Notes. First period: one-sided proportion of t-tests for first choice accommodation. Wilcoxon rank-sum test for stable outcome. All Periods: one-sided permutation tests.

that in the baseline treatment in first period, it is also significantly higher in the advice treatment compared to the baseline treatment over all periods.

Support. Table 9 presents the proportions of subjects who obtain their most preferred objects in the first period and over all periods. $P$-values are computed from one-sided proportion of t-tests using individuals as independent observations and from one-sided permutation tests using sessions as independent observations.

In the first period, only $11.1 \%$ of participants obtain their most preferred objects in the baseline treatment, while $41.7 \%$ of participants are accommodated to their true top choices in the advice treatment and in the observation treatment, receptively. One-sided $t$-tests of proportions with the null hypothesis of equal proportion are rejected in favor of $H_{a}$ : Base $<$ Ad. and $H_{a}$ : Base $<$ Ob., with $p$-values $=0.002$. Over all periods, on average, $57.4 \%$ of participants receive their most preferred objects in the baseline treatment, while $85.4 \%$ and $80.7 \%$ of participants receive their true top choices in the advice treatment and in the observation treatment, respectively. One-sided permutation test with the null hypothesis of equal proportion is rejected in favor of $H_{a}$ : Base $<$ Ad., with $p$-value $=0.040$. However, we cannot reject null hypothesis of equal proportion for Base and $\mathrm{Ob}$. and for Ob. and Ad., as $p$-values $>0.05$.

The high rate of first choice accommodation is mainly due to the high truth-telling rate because of the positive link between the two. The more likely subjects play truthfully in the advice and observation treatments, the higher chance for them to obtain their most preferred objects. This provides an explanation why subjects would like to adopt and stick to truth-telling in the advice and observation treatment. 


\subsubsection{Stability}

As market designers in matching problem aim at implementing stable outcomes, it is important to evaluate whether the Deferred Acceptance mechanism will generate stable outcome with submitted preferences in the lab, and if so, what stable outcome is more likely to be reached. In our specific environment, there are two stable outcomes, which are Pareto ranked. The Deferred Acceptance mechanism should generate Pareto efficient outcome $\mu_{u}^{S}$ when all subjects play truthfully. As we observe a certain number of subjects misrepresenting their preferences, there will be some outcomes that are not $\mu_{u}^{S}$. How many outcomes are not $\mu_{u}^{S}$, and whether these outcomes are unstable or not are of great importance. To evaluate stability, I compute the proportion of markets (i.e., groups) which result in stable outcomes per period.

Figure 4 presents the proportions of outcomes that are stable across three treatments, which are the sum of the proportions of Pareto efficient stable outcome $\mu_{u}^{S}$ and the proportions of Pareto inferior stable outcome $\mu_{u}^{O}$. It can be seen from Figure 4 that in most periods, most of markets end in stable outcomes. There are a certain number of unstable outcomes in the first few periods in the baseline treatment and in the observation treatment. The unstable outcome is mainly due to irrational behavior adopted by some subjects in their groups. While there is a high rate of stability, a great number of stable outcomes are Pareto inferior. However, as the game is repeated over time, the proportion of Pareto inferior outcome decreases, with the majority of outcomes being Pareto efficient stable ones. Next, I will focus on the treatment effect on stability.

Result 4 (Uncorrelated Preference: Stability). The average proportion of stable outcomes is significantly higher in the advice treatment and in the observation treatment than that in the baseline treatment over all periods. The proportion of optimal stable outcomes in the advice treatment is significantly higher than that in the baseline treatment in the first period and over all periods.

Support. Table 9 presents the proportion of stable outcomes, the proportion of Pareto optimal stable outcomes, as well as the proportion of Pareto inferior outcomes across three treatments. $P$ values are computed from Wilcoxon rank-sum test using groups as independent observations and from one-sided permutation tests using sessions as independent observations. Only $p$-values for the proportion of stable outcome are reported in the table.

In the first period, $91.7 \%$ of outcomes are stable in the baseline treatment, however, only $8.3 \%$ of them are Pareto optimal stable outcomes. On the contrary, $41.7 \%$ and $33.3 \%$ are Pareto efficient stable outcomes in the advice treatment and in the observation treatment, respectively. There are also $25 \%$ of unstable outcomes in the observation treatment, indicating subjects failing to coordinate on Nash equilibria. Wilcoxon rank-sum test with the null hypothesis of equal proportion of the stable outcome is rejected in favor of $H_{a}$ : Ob. $<$ Ad., with $p$-value $=0.035$. Meanwhile, test with the null hypothesis of equal proportion of the Pareto efficient stable outcome is also 


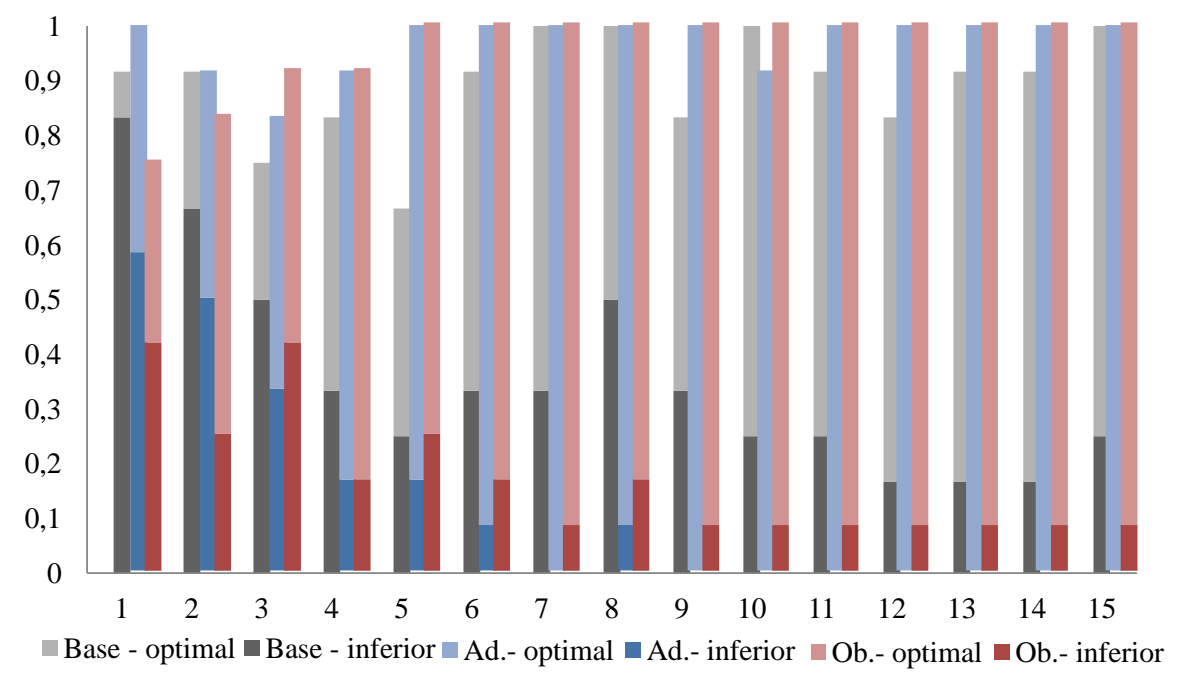

Figure 4: Uncorrelated Preference: Proportion of Stable Outcome across Treatments 
rejected in favor of $H_{a}$ : Base $<$ Ad., with $p$-value $=0.032$. Over all periods, on average, $89.4 \%$ of outcomes are stable in the baseline treatment, with Pareto efficient outcomes being 53.9\%. On the other hand, the proportions of Pareto optimal stable outcomes reach to $84.4 \%$ and $79.4 \%$ in the advice treatment and in the observation treatment, respectively. One-sided permutation tests with the null hypothesis of equal proportion of stable outcome are rejected in favor of $H_{a}$ : Base $<$ Ad. and $H_{a}$ : Base $<$ Ob., with $p$-value $=0.040$. Meanwhile, test with the null hypothesis of equal proportion of the Pareto efficient stable outcome is also rejected in favor of $H_{a}$ : Base $<$ Ad., with $p$-value $=0.004$. However, we cannot reject null hypothesis of equal proportion for Ob. and Ad., as $p$-values $>0.05$.

By Result 4 , we can partly reject null in favor of Hypothesis 3 that it is more likely to obtain Pareto efficient stable outcome in the advice treatment than that in the baseline treatment. This is mainly due to the number of subjects who reveal their preferences is greater in the advice treatment, thus they are more likely to coordinate on this Pareto efficient outcome.

\subsubsection{Efficiency}

For welfare concern, I would like to evaluate efficiency in this section. I mainly use two measures to determine the levels of efficiency. Actual efficiency is computed as subject's average payoff. Normalized efficiency is defined in the following: 14

I first sum up individuals payoff in each group in each period, which is referred to as actual sum of payoffs, and then compute the minimum sum of payoffs and maximum sum of payoffs that the game can generate, which is 120 and 600, respectively. Efficiency is then normalized according to the following formula:

$$
\text { Normalized Efficiency }=\frac{\text { Actual sum of payoffs }- \text { Minimum sum of payoffs }}{\text { Maximum sum of payoffs }- \text { Minimum sum of payoffs }}
$$

Figure 5 presents subject's average payoff (upper panel) as well as normalized efficiency (lower panel). We can observe that for both actual efficiency and normalized efficiency measures, efficiency levels in the baseline treatment are always lower than those in the advice treatment and in the observation treatment. More interestingly, the advice treatment has the highest efficiency level, which remains close to Pareto efficient in last five periods. In contrast, whereas the efficiency levels of the baseline treatment and the observation treatment increase quickly over time and remain stable for last five periods, there is still certain distance to Pareto efficient outcome. This is because

\footnotetext{
${ }^{14}$ I also compute the ratio of actual group payoffs and Pareto efficient payoffs, as well as rank-based efficiency, because matching game only needs ordinal preference information. These measures have similar results as the two measures presented in the paper.
} 
a certain fraction of outcomes are Pareto inferior or unstable in these two treatments in last five periods.

Table 10: Uncorrelated Preference: Actual Efficiency and Normalized Efficiency

\begin{tabular}{|c|c|c|c|c|c|c|}
\hline & \multicolumn{3}{|c|}{ Actual Efficiency } & \multicolumn{3}{|c|}{ Normalized Efficiency } \\
\hline First period & Payoff & $H_{a}$ & $P$-value & Index & $H_{a}$ & $P$-value \\
\hline Base & 126,667 & Base $<$ Ad. & 0,001 & 0,542 & Base $<$ Ad. & 0,032 \\
\hline Ad. & 153,333 & Base $<$ Ob. & 0,013 & 0,708 & Base $<$ Ob. & 0,070 \\
\hline Ob. & 146,667 & Ob. < Ad & 0,343 & 0,667 & Ob. < Ad. & 0,340 \\
\hline All Periods & & & & & & \\
\hline Base & 163,111 & Base $<$ Ad. & 0,040 & 0,769 & Base $<$ Ad. & 0,040 \\
\hline Ad. & 187,556 & Base $<$ Ob. & 0,210 & 0,922 & Base $<$ Ob. & 0,210 \\
\hline Ob. & 183,556 & Ob. $<$ Ad. & 0,420 & 0,897 & Ob. < Ad. & 0,420 \\
\hline
\end{tabular}

Notes. First period: Wilcoxon rank-sum test. All Periods: one-sided permutation tests.

Result 5 (Uncorrelated Preference: Efficiency). The efficiency level in the advice treatment is significantly higher than that in the baseline treatment.

Support. Table 10 presents actual efficiency levels as well as normalized efficiency levels for each of three treatments in first period and over all periods. $P$-values are computed from Wilcoxon rank-sum test using individuals as observations for actual efficiency levels, and using groups as observations for normalized efficiency level, and from one-sided permutation tests using sessions as observations.

In the first period, each subject on average earns 127 experimental points in the baseline treatment, while the average payoffs are 153 experimental points and 147 experimental points in the advice treatment and in the observation treatment, respectively. Wilcoxon rank-sum test with the null hypothesis of equal distributions of actual payoffs are rejected in favor of $H_{a}$ : Base $<\mathrm{Ad}$. and $H_{a}$ : Base $<$ Ob., with $p$-value $<0.013$. Over all periods, the average payoff for each subject is 163 experimental points in the baseline treatment, 188 experimental points for the advice treatment, and 184 experimental points for the observation treatment, respectively. One-sided permutation test with the null hypothesis of equal distributions of actual payoffs is rejected in favor of $H_{a}$ : Base $<$ Ad., with $p$-value $=0.040$. Tests on normalized efficiency have similar results.

Efficiency results are consistent with stability findings, as the advice treatment has the largest number of Pareto efficient outcomes, due to highest truth-telling rate. To sum up, subjects in the advice treatment are more likely to reveal their true preferences, thus resulting in more Pareto efficient outcomes, which increases welfare in terms of first choice accommodation (rank based efficiency) and payoff based efficiency. 

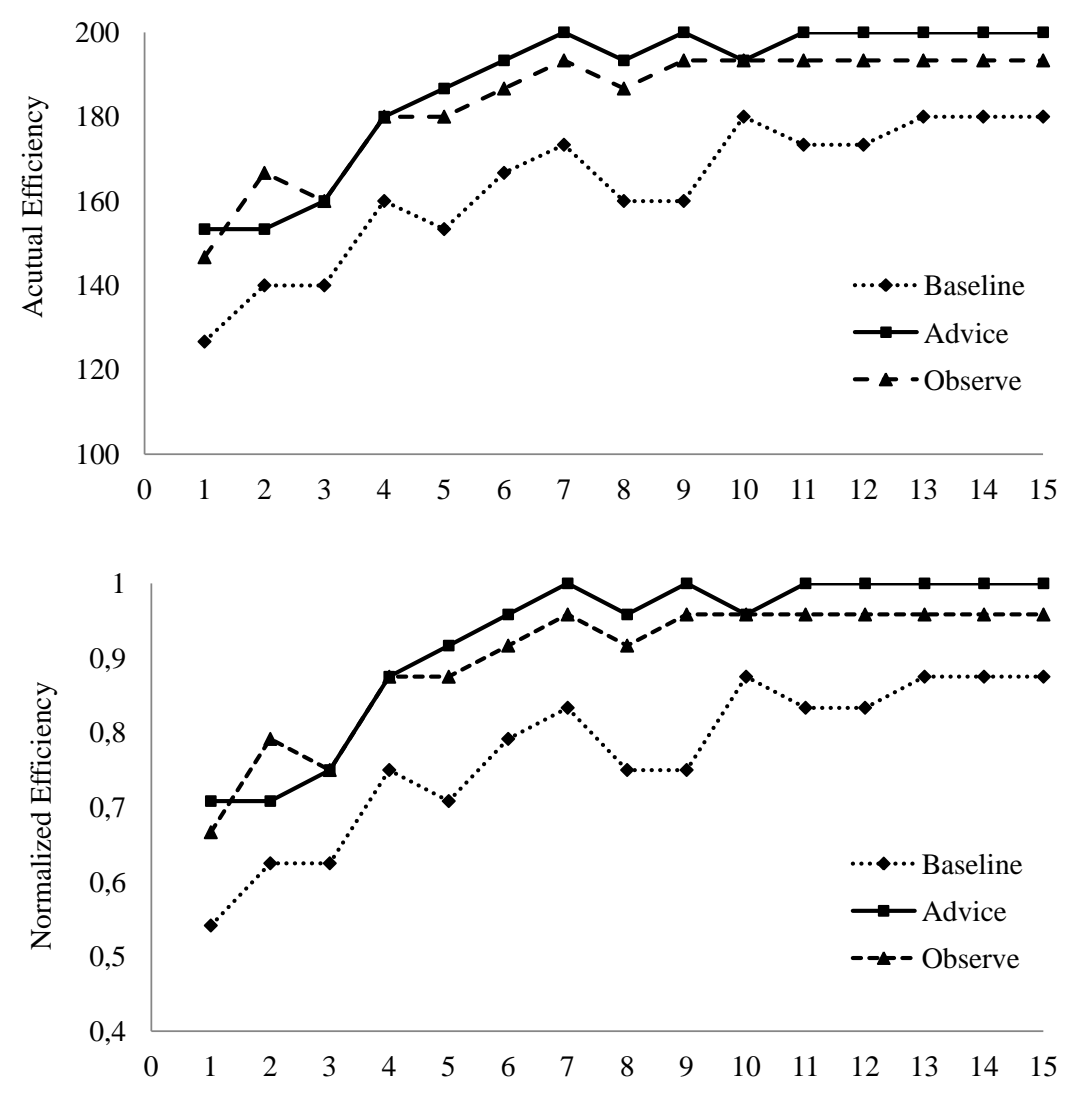

Figure 5: Uncorrelated Preference: Actual Efficiency and Normalized Efficiency across Treatments 


\subsection{Correlated Preference Environment}

\subsubsection{Individual Behavior}

Next I will discuss results of individual behavior in the correlated preference environment. It can be seen from Figure 6 that truth-telling is also the most salient behavior in the correlated preference environment. The ranking of treatments in the truth-telling follows the order of Ad. Base $>$ Ob.. The proportion of truthful preference revelation in the advice treatment is also the highest, which is $69.4 \%$ in the first period. Interestingly, truth-telling rate in the first period is $41.7 \%$ in the observation treatment, even lower than that in the baseline treatment, which is $52.8 \%$. Furthermore, safety choice bias is prevalent in the correlated preference environment, in which the ranking of three treatments follows the order of Ob. $>$ Base $\sim$ Ad..
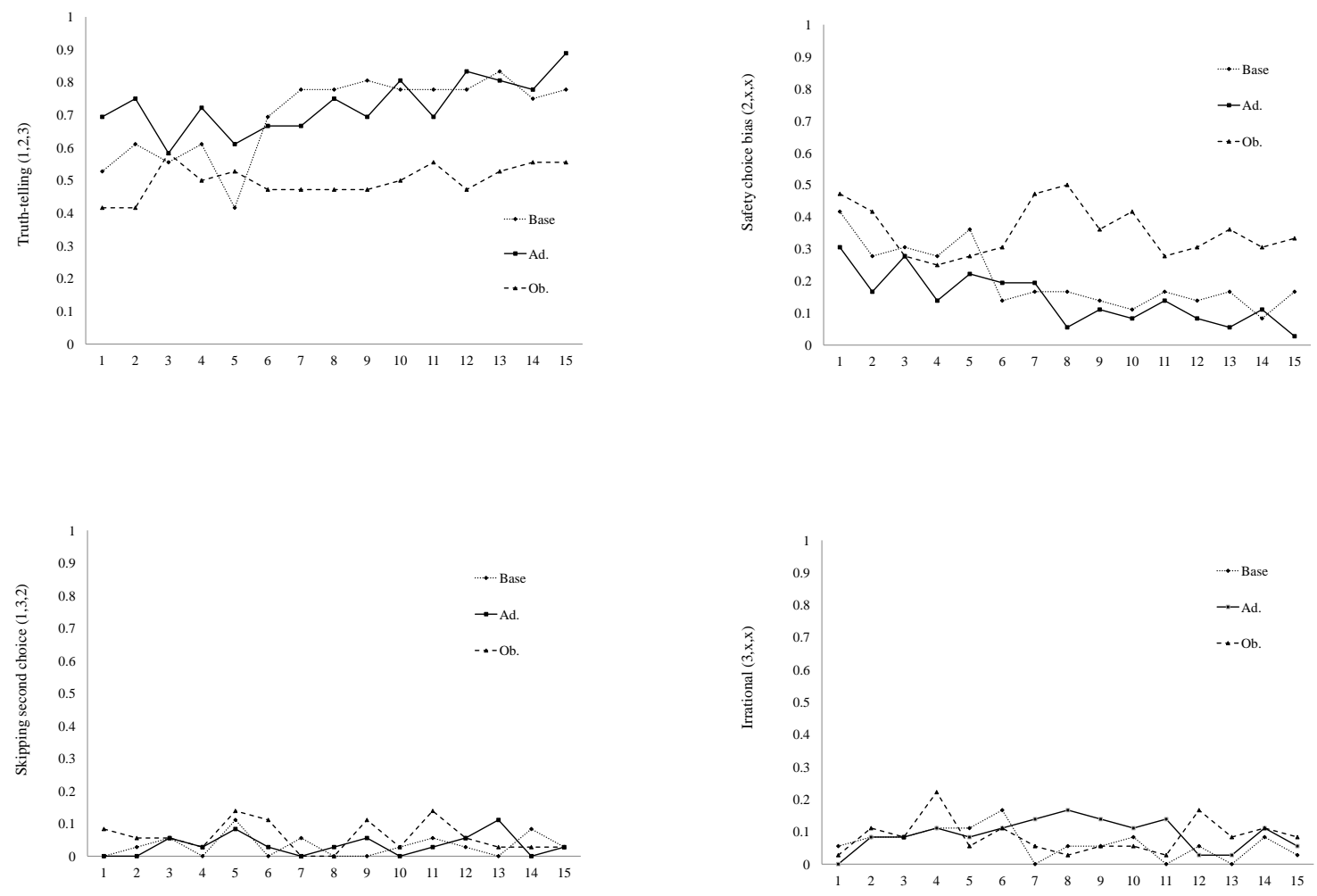

Figure 6: Correlated Preference: Empirical Distributions of Submitted Rankings across Treatments Result 6 (Correlated Preference: Truthful Preference Revelation). In the correlated preference environment, the proportion of truthful preference revelation in the advice treatment is higher than that in the baseline treatment in the first period, although the difference is not statistically significant. Truth-telling rate in the observation treatment is significantly lower than that in the advice treatment in the first period. 
Support. Table 11 presents the proportions of truthful preference revelation, as well as the proportions of safety choice bias for the first period in the correlated preference environment. $P$-values are computed from one-sided proportion of t-tests using individuals as independent observations. In the first period, $52.8 \%$ of participants reveal their true preferences in the baseline treatment, while $69.4 \%$ and $41.7 \%$ of participants play truthfully in the advice treatment and in the observation treatment, respectively. One-sided $t$-test of proportions with the null hypothesis of equal proportion is rejected in favor of $H_{a}$ : Ob. $<$ Ad., with $p$-values $=0.009$. We cannot reject null hypothesis of equal proportion for Base and Ad. at $5 \%$ significant level, as $p$-value $=0.074$. I also conduct six probit regressions in Table 12 to check the average treatment effect over all periods. In specification (1) of Table 12, the coefficient of Advice is insignificant, but the coefficient of Observation is negative and significant. However, in specifications (2) and (3), coefficients of Advice and Observation are insignificant.

Table 11: Correlated Preference: Proportions of Truth-telling and Safety Choice Bias

\begin{tabular}{|c|c|c|c|c|c|c|}
\hline & \multicolumn{3}{|c|}{ Truth-telling } & \multicolumn{3}{|c|}{ Safety Choice Bias } \\
\hline First period & Proportion & $H_{a}$ & $P$-value & Proportion & $H_{a}$ & $P$-value \\
\hline Base & 0.528 & Base $<$ Ad & 0.074 & 0.417 & Base $>$ Ad. & 0.163 \\
\hline Ad. & 0.694 & Ob. $<$ Base & 0.173 & 0.306 & Ob. $>$ Base & 0.318 \\
\hline $\mathrm{Ob}$. & 0.417 & Ob. $<$ Ad. & 0.009 & 0.472 & Ob. $>$ Ad. & 0.074 \\
\hline
\end{tabular}

Notes. First period: one-sided proportion of t-tests using individuals as observations.

The proportions of safety choice bias are also more prevalent in the correlated preference environment compared to the uncorrelated preference environment. It can be seen from Figure 6 that the proportion of safety choice bias is $47.2 \%$ in the first period of the observation treatment. In comparison, subjects are less likely to play safety choice bias in the baseline treatment and in the advice treatment than those in the observation treatment.

Result 7 (Correlated Preference: Safety Choice Bias). In the correlated preference environment, there is no significant difference on safety choice bias across three treatments.

Support. Over all periods, on average, $35.6 \%$ of participants have safety choice bias in the observation treatment, while $20.6 \%$ and $14.4 \%$ of participants misrepresent their preferences in the baseline treatment and in the advice treatment, respectively. From Table 11, we cannot reject null hypothesis of equal proportion based on one-sided $t$-test of proportions. In specifications (4) through (6) in Table 12, coefficients of Advice and Observation are also insignificant.

By Results 6 and 7, we can not reject null in favor that subjects are more likely to reveal their true preferences in the advice treatment and in the observation treatment than those in the baseline 
Table 12: Truth-telling and Safety Choice Bias: Probit Regressions

\begin{tabular}{lccccccc}
\hline \hline & \multicolumn{3}{c}{ Truth-telling } & & \multicolumn{3}{c}{ Safety Choice Bias } \\
\hline \multirow{3}{*}{ Advice } & $(1)$ & $(2)$ & $(3)$ & & $(4)$ & $(5)$ & $(6)$ \\
& 0.033 & 0.090 & 0.090 & & -0.071 & -0.058 & -0.059 \\
Observe & $(0.061)$ & $(0.058)$ & $(0.058)$ & & $(0.059)$ & $(0.055)$ & $(0.057)$ \\
& $-0.187^{* *}$ & -0.056 & -0.056 & & $0.134^{*}$ & 0.016 & 0.018 \\
Period & $(0.079)$ & $(0.037)$ & $(0.036)$ & & $(0.077)$ & $(0.036)$ & $(0.037)$ \\
& $0.013^{* * *}$ & $0.022^{* * *}$ & $0.022^{* * *}$ & & $-0.012^{* * *}$ & $-0.018^{* * *}$ & $-0.015^{* * *}$ \\
Advice $\times$ Period & $(0.004)$ & $(0.001)$ & $(0.002)$ & & $(0.004)$ & $(0.003)$ & $(0.002)$ \\
& & $-0.008^{* * *}$ & $-0.008^{* * *}$ & & -0.002 & -0.002 \\
Observene Period & & $(0.001)$ & $(0.001)$ & & $(0.003)$ & $(0.003)$ \\
& & $-0.017^{*}$ & $-0.017^{*}$ & & & $0.015^{* *}$ & $0.015^{* * *}$ \\
Period 1 & & $(0.009)$ & $(0.009)$ & & $(0.008)$ & $(0.008)$ \\
& & & 0.001 & & & $0.076^{* *}$ \\
& & & $(0.056)$ & & & $(0.034)$ \\
\hline \hline
\end{tabular}

Notes. Standard errors in parentheses are clustered at the session. Coefficients are marginal effects. $* * * \mathrm{p}<0.01, * * \mathrm{p}<0.05, * \mathrm{p}<0.1$.

treatment in the correlated preference environment. In fact, subjects are also more likely to reveal their preference truthfully when having advice from their peers $(69.4 \%$ in the advice treatment v.s. $52.8 \%$ in the baseline treatment in the first period) in the correlated preference environment, although the difference is not statistically significant. It is notable that for baseline treatment, firstperiod truth-telling rate in the correlated preference environment is significantly lower than that in the uncorrelated preference environment, while there is no significant difference on first-period truth-telling rate in the advice treatment between the two environments. Interestingly, subjects are less likely to play truthfully in the observation treatment than the other two treatments, and this is probably because subjects does not observe the dominance of truth-telling from their predecessors.

With repetition, subjects are also more likely to play truthfully in the correlated preference environment. The coefficients of variable Period in specifications (1) through (3) in Table 12 are $0.013(p<0.01), 0.022(p<0.01)$ and $0.022(p<0.01)$, indicating that the proportion of truthtelling increases by about $2 \%$ per period. We also find that, coefficients of variable Advice $\times$ Period in specifications (2) and (3) are negative and significant, indicating period effect is smaller in the advice treatment than that in the baseline treatments. Similarly, in specifications (4) through (6) of Table 12, coefficients of variable Period are significant and negative, indicating that the proportion of safety choice bias decreases by $1.5 \%$ per period.

Furthermore, Figure 7 presents the proportions of subjects who always play truthfully since 
that period. Compared to that in the uncorrelated preference environment, subjects are more likely to switch with other strategies rather than to stick to truth-telling in the correlated preference environment to the extent that this proportion does not stabilize until last period. Nevertheless, with time going on, more and more subjects would like to stick to truth-telling behavior as well, with the truth-telling rate increasing to $77.8 \%$ in the last period of the baseline treatment.

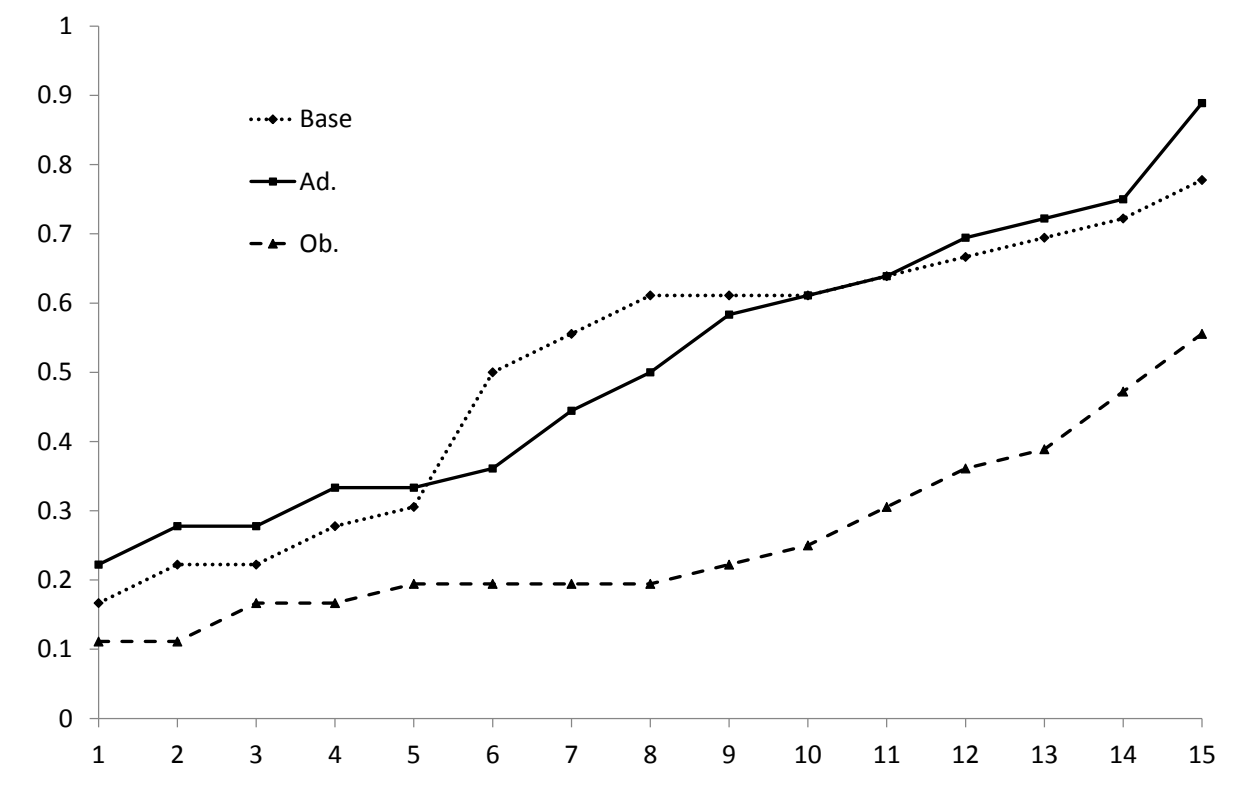

Figure 7: Correlated Preference: Proportion of Subjects Who Always Play Truthfully Since that Period

Table 13 presents the histogram of strategies that participants in the baseline treatment advise to play. Similar to uncorrelated preference environment, the majority of subjects in the correlated preference environment, which is $75 \%$, advise successors of their own types to submit their preferences truthfully, although this rate is lower than that in the uncorrelated preference environment. There are also $19.5 \%$ of subjects suggesting to play safety choice bias in the correlated preference environment, which is higher than that in the uncorrelated preference environment. Moreover, like the uncorrelated preference environment, most of subjects advise what they have played in the correlated preference environment as well. For example, it is shown from Table 14 that, among subjects who submit their true preferences, $92.9 \%$ of them advise their successors to play truthfully, while the rest suggest on playing safety choice bias. The majority of subjects who play safety choice bias still suggest on safety choice bias. Table 13 further shows that most of subjects would 
like to take advice given to them in the correlated preference environment. However, subjects are less likely to play truthfully and are more likely to play safety choice than advised. Moreover, no subject plays irrational behavior in the first period when having advice.

Table 13: Correlated Preference: Empirical Distributions of Behaviors and Advice in the Baseline and Advice Treatments

\begin{tabular}{lcccccc}
\hline \hline Baseline treatment: & $(1,2,3)$ & $(1,3,2)$ & $(2,1,3)$ & $(2,3,1)$ & $(3,1,2)$ & $(3,2,1)$ \\
\hline Behavior in last 5 periods & 0.783 & 0.039 & 0.094 & 0.050 & 0.022 & 0.011 \\
Behavior in last period & 0.778 & 0.028 & 0.111 & 0.056 & 0.028 & 0.000 \\
Given advice & 0.750 & 0.028 & 0.139 & 0.056 & 0.028 & 0.000 \\
\hline Advice treatment: & $(1,2,3)$ & $(1,3,2)$ & $(2,1,3)$ & $(2,3,1)$ & $(3,1,2)$ & $(3,2,1)$ \\
\hline Behavior in first period & 0.694 & 0.000 & 0.250 & 0.056 & 0.000 & 0.000 \\
Behavior in first 5 periods & 0.672 & 0.033 & 0.194 & 0.028 & 0.061 & 0.011 \\
\hline \hline
\end{tabular}

Table 14: Correlated Preference: Distributions of Advice Conditional on Behaviors in Last Period

\begin{tabular}{ccccccc}
\hline \hline Behavior\Advice & $(1,2,3)$ & $(1,3,2)$ & $(2,1,3)$ & $(2,3,1)$ & $(3,1,2)$ & $(3,2,1)$ \\
\hline$(1,2,3)$ & 0.929 & 0.000 & 0.036 & 0.036 & 0.000 & 0.000 \\
$(1,3,2)$ & 0.000 & 1.000 & 0.000 & 0.000 & 0.000 & 0.000 \\
$(2,1,3)$ & 0.250 & 0.000 & 0.750 & 0.000 & 0.000 & 0.000 \\
$(2,3,1)$ & 0.000 & 0.000 & 0.000 & 0.500 & 0.500 & 0.000 \\
$(3,1,2)$ & 0.000 & 0.000 & 1.000 & 0.000 & 0.000 & 0.000 \\
$(3,2,1)$ & 0.000 & 0.000 & 0.000 & 0.000 & 0.000 & 0.000 \\
\hline \hline
\end{tabular}

To examine why the majority of subjects play truthfully and why truth-telling rate is lower in the correlated preference environment, I calculate subjects' respective payoffs for playing truthfully and safety choice bias in the correlated preference environment. Over all periods, among those who submit truthful preferences, on average, only $12.7 \%$ (9.9\% and $11.9 \%)$ of subjects obtain their most preferred objects, and $87.3 \%$ (90.1\% and $88.1 \%$ ) of them obtain their second preferred objects in the baseline treatment (the advice treatment and the observation treatment). The average earning for playing truthfully is thus 127.4 points (126.2 points and 123 points) in the baseline treatment (the advice treatment and the observation treatment). On the other hand, for subjects who play safety choice bias, all of them obtain their second preferred objects, and the average earning is 120 points accordingly. Therefore, there is no payoff difference between truth-telling and safety choice bias most of the time. This probably explains why subjects are less likely to play truthfully in the correlated preference environment, and why there is no significant increase in truth-telling when advised to do so.

Furthermore, as subjects of Type 2 have same payoffs by playing safety choice bias as truthtelling, it is interesting to check whether Type 2 are more likely to play truthfully or to play safety choice bias. While truth-telling is weakly dominant strategy for subjects of Type1 and Type3, 
we do not find subjects of Type 2 less likely to play truthfully compared to two other types in the baseline treatment. Interestingly, while $75 \%$ of Type 2 subjects advise subjects of their own types to play truthfully. ${ }^{15}$ subjects of Type 2 in the advice treatment are less likely to follow advice given by their predecessors and play truthfully compared to two other types. ${ }^{16}$ In comparison, when observing what their predecessors have played and have earned, subjects of Type 2 are more likely to play truthfully compared to two other types in the observation treatment 17

\subsubsection{First Choice Accommodation}

In correlated preference environment, the efficient outcome is that subjects of Type 1 and Type 3 obtain their most preferred objects, and subjects of Type 2 obtains their second preferred objects. Therefore, the proportion of first choice accommodation lies between 0 and $\frac{2}{3}$.

Figure 8 presents the cumulative distributions of actual outcomes for each of three treatments in the correlated preference environment. It can be seen from Figure 8 that only a small fraction of subjects obtain their most preferred objects.

Table 15: Correlated Preference: Proportions of First Choice Accommodation and Stable Outcomes

\begin{tabular}{|c|c|c|c|c|c|c|c|}
\hline \multirow[b]{2}{*}{ First period } & \multicolumn{2}{|c|}{ 1st Choice Accom. } & \multicolumn{4}{|c|}{ Nash Equilibrium Outcomes } & \multirow[b]{2}{*}{$H_{a}$} \\
\hline & Proportion & $P$-value & Stable & Efficient & $\mathrm{NE}$ & $P$-value & \\
\hline Base & 0.028 & 0.314 & 0.917 & 0 & 0.917 & 0.317 & Base $\neq$ Ad. \\
\hline Ad. & 0 & 1.000 & 1 & 0 & 1 & 1.000 & Base $\neq$ Ob. \\
\hline Ob. & 0.028 & 0.314 & 0.917 & 0 & 0.917 & 0.317 & Ob. $\neq$ Ad \\
\hline \multicolumn{8}{|l|}{ All Periods } \\
\hline Base & 0.098 & 0.750 & 0.822 & 0.078 & 0.900 & 0.840 & Base $\neq$ Ad \\
\hline Ad. & 0.083 & 0.630 & 0.856 & 0.061 & 0.917 & 0.790 & Base $\neq$ Ob. \\
\hline Ob. & 0.074 & 1.000 & 0.844 & 0.022 & 0.867 & 0.830 & Ob. $\neq \mathrm{Ad}$ \\
\hline
\end{tabular}

Notes. First period: two-sided proportion of t-tests for first choice accommodation. Wilcoxon rank-sum test for stable outcome. All Periods: two-sided permutation tests.

Result 8 (Correlated Preference: First-choice accommodation). Only a small fraction of subjects are accommodated to their most preferred objects in the correlated preference environment. There is no significant difference in the proportions of first choice accommodation across three treatments.

\footnotetext{
${ }^{15} 66.7 \%$ of Type 1 subjects and $83.3 \%$ of Type 3 subjects suggest on truth-telling.

${ }^{16} 76.1 \%$ of Type 1 subjects, $60.6 \%$ of Type 2 subjects and $82.2 \%$ of Type 3 subjects reveal their preferences truthfully in the advice treatment.

${ }^{17} 48.9 \%$ of Type 1 subjects, $60 \%$ of Type 2 subjects and $41.1 \%$ of Type 3 subjects reveal their preferences truthfully in the observation treatment.
} 


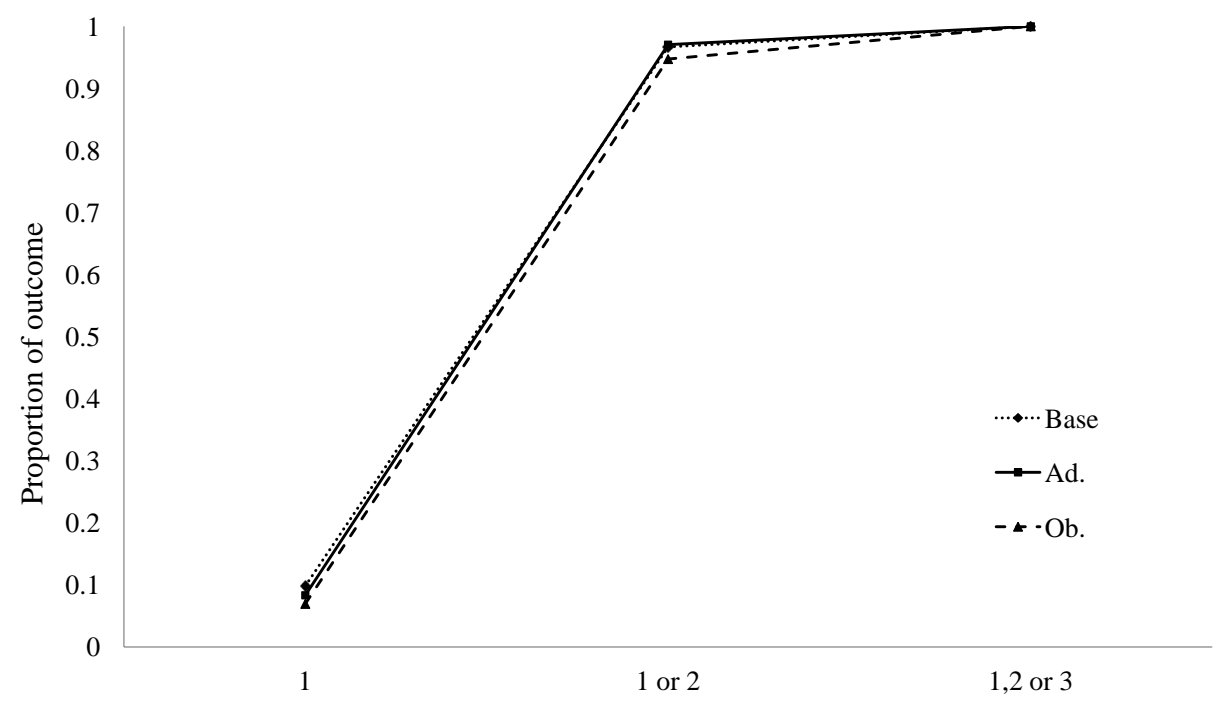

Figure 8: Correlated Preference: CDFs of True Choice Accommodation with Submitted Preferences 
Support. Table 15 presents the proportions of subjects who obtain their most preferred objects in the first period and over all periods. $P$-values are computed from two-sided proportion of t-tests using individuals as independent observations and from two-sided permutation tests using sessions as independent observations. In the first period, only $2.8 \%$ of participants obtain their most preferred objects in the baseline treatment and observation treatment, respectively, while no one is accommodated to their true top choice in the advice treatment. Over all periods, on average, only $9.8 \%, 8.3 \%$ and $7.4 \%$ of participants obtain their most preferred objects in the baseline treatment, the advice treatment and the observation treatment, respectively. Moreover, we can not rejected null hypothesis of equal proportion across three treatments.

In fact, the majority of subjects are accommodated to their second preferred objects across all three treatments in the correlated preference environment. This is probably because subjects are more likely to coordinate on the stable Nash equilibrium outcome compared to efficient Nash equilibrium outcome. To answer this question, I will further check which NE equilibrium outcome is more likely to be selected in this environment.

\subsubsection{Stability}

There are two Nash equilibrium outcomes in the correlated preference environment, one being stable and the other being Pareto efficient. On the one hand, stability is important for the success of the matching market (Roth, 1991; Kagel and Roth, 2000), as no participant disagrees on current outcome and wants to transact outside of the system. On the other hand, participants have optimal welfare in the efficient outcome, although this outcome is unstable. Therefore, it is interesting to see whether the stable outcome $\mu_{c}^{S}$ or the efficient outcome $\mu_{c}^{E}$ is more likely to be selected.

Figure 9 presents the proportions of stable outcome $\mu_{c}^{S}$ and the proportions of Pareto efficient outcome $\mu_{c}^{E}$ in the correlated preference environment. It can be seen from Figure 9 that in most periods, most of markets end in stable outcomes. There is also a small fraction of markets achieving Pareto efficient outcome, however, this fraction is significantly less than that of stable outcome. Furthermore, we do not find any significant difference in proportions of stable outcomes and Nash equilibrium outcomes across three treatments in the correlated preference environment.

Result 9 (Correlated Preference: Stability). Stable outcome is more likely to be selected in the correlated preference environment. There is not significant difference in the proportions of stable outcomes across three treatments in the correlated preference environment.

Support. Table 15 presents the proportion of stable outcomes, the proportion of Pareto efficient outcomes, as well as the proportion of Nash equilibrium outcomes across three treatments in the correlated preference environment. $P$-values are computed from Wilcoxon rank-sum test using 


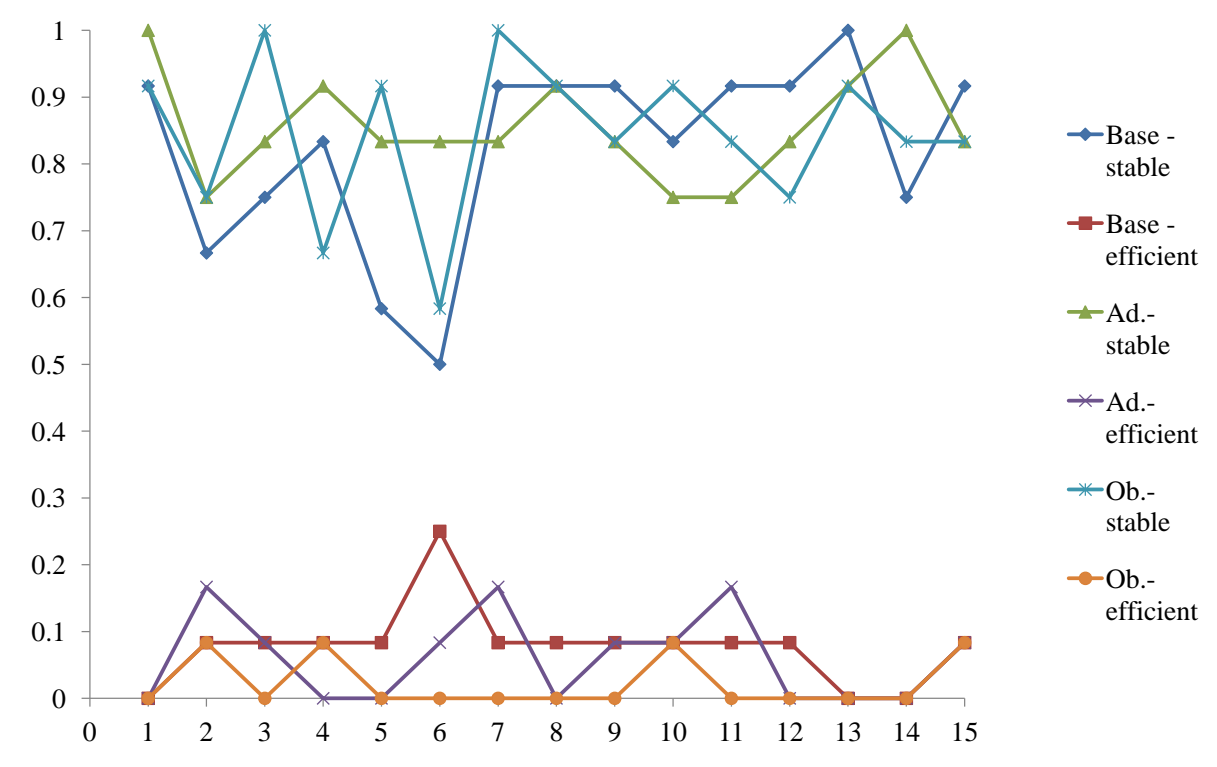

Figure 9: Correlated Preference: Proportion of Stable Outcome and Pareto Efficient Outcome across Treatments 
groups as independent observations and from two-sided permutation tests using sessions as independent observations. Only $p$-values for the proportion of stable outcome are reported in the table. In the first period, $91.7 \%, 100 \%$ and $91.7 \%$ of outcomes are stable in the baseline treatment, the advice treatment and the observation treatment, respectively. Over all periods, on average, $82.2 \%$, $85.6 \%$ and $84.4 \%$ of outcomes are stable, and $7.8 \%, 6.1 \%$ and $2.2 \%$ of outcomes are efficient outcomes in the baseline treatment, the advice treatment and the observation treatment, respectively. Moreover, we can not reject the null hypothesis of equal proportion of the stable outcome across three treatments.

\subsubsection{Efficiency}

This section presents results of efficiency across three treatments in the correlated preference environment. In the correlated preference environment, Normalized efficiency is calculated that the minimum sum of payoffs and maximum sum of payoffs is 200 and 520, respectively.

Figure 10 presents subject's average payoff (upper panel) and normalized efficiency (lower panel). In line with the proportion of Nash equilibrium outcomes, there is no significant difference in efficiency levels across three treatments. Furthermore, the average payoff is around 120 points per subject, indicating that most of subjects obtain their second most preferred objects. 

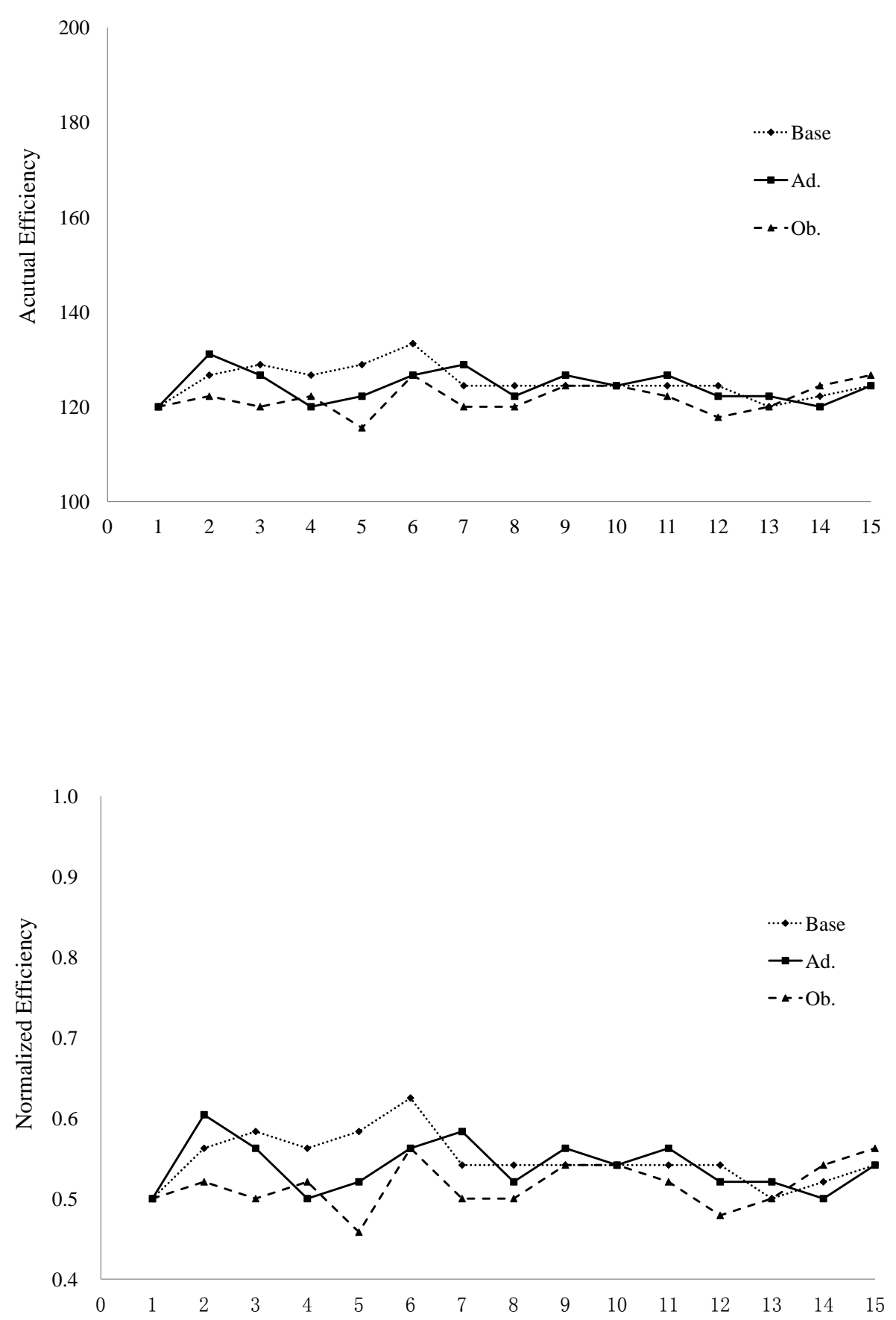

Figure 10: Correlated Preference: Actual Efficiency and Normalized Efficiency across Treatments 
Table 16: Correlated Preference: Actual Efficiency and Normalized Efficiency

\begin{tabular}{|c|c|c|c|c|c|c|}
\hline & \multicolumn{3}{|c|}{ Actual Efficiency } & \multicolumn{3}{|c|}{ Normalized Efficiency } \\
\hline First period & Payoff & $H_{a}$ & $P$-value & Index & $H_{a}$ & $P$-value \\
\hline Base & 120 & Base $\neq$ Ad. & 1.000 & 0.5 & Base $\neq$ Ad. & 1.000 \\
\hline Ad. & 120 & Base $\neq=\mathrm{Ob}$ & 1.000 & 0.5 & Base $\neq$ Ob. & 1.000 \\
\hline Ob. & 120 & Ob. $\neq$ Ad. & 1.000 & 0.5 & Ob. $\neq$ Ad & 1.000 \\
\hline \multicolumn{7}{|l|}{ All Periods } \\
\hline Base & 125.2 & Base $\neq$ Ad. & 1.000 & 0.549 & Base $\neq$ Ad. & 1.000 \\
\hline Ad. & 124.3 & Base $\neq=\mathrm{Ob}$ & 0.400 & 0.540 & Base $\neq$ Ob. & 0.400 \\
\hline Ob. & 121.8 & $\mathrm{Ob} . \neq \mathrm{Ad}$ & 0.450 & 0.517 & $\mathrm{Ob} . \neq \mathrm{Ad}$ & 0.450 \\
\hline
\end{tabular}

Notes. First period: Wilcoxon rank-sum test. All Periods: two-sided permutation tests.

Result 10 (Correlated Preference: Efficiency). There is no significant difference in efficiency level across treatments in the correlated preference environment.

Support. Table 16 presents actual efficiency levels as well as normalized efficiency levels for each of three treatments in first period and over all periods. $P$-values are computed from Wilcoxon rank-sum test using individuals as observations for actual efficiency levels, and using groups as observations for normalized efficiency level, and from two-sided permutation tests using sessions as observations. In the first period, each subject on average earns 120 experimental points in each of the three treatments. Over all periods, the average payoff for each subject is 125.2, 124.3 and 121.8 experimental points in the baseline treatment, the advice treatment and the observation treatment, respectively. Moreover, we can not reject the null hypothesis of equal distributions of actual payoffs as well as equal distributions of normalized efficiency across three treatments.

\section{Conclusion}

Whereas the matching problem is a one-shot game, people in reality usually consult those who have participated in previous markets about optimal strategies. This paper investigates whether highly experienced subjects would like to transmit what they have learned to their successors and encourage them to play truthfully under the DA mechanism. In this experiment, subjects repeatedly play the matching game induced by the Deferred Acceptance mechanism for a finite number of periods, and then are invited to give advice about the best strategy to subjects who will participate in the same experiment in later sessions and who have the same types as themselves. Participants in successive sessions are either given advice from their predecessors or can observe what their predecessors have played and what they have earned in previous sessions.

I find that even in the simplest environment, only a small number of subjects reveal their true 
preferences in the first period, when having no experience of their own or from peers. Nevertheless, with ample repetition, subjects learn to play truthfully through their own experience in the uncorrelated preference environment as well as in the correlated preference environment. Moreover, the majority of subjects would like to transmit what they have learned to their successors by advising on truth-telling in both environments. However, the effect of experience transmission on truth-telling behavior depends on transmission channels as well as environments. On the one hand, while subjects are more likely to play truthfully when having predecessors' advice in both environments if compared to the other two treatments, this effect is not significant in the correlated preference environment. On the other hand, while observing past matches can significantly increase truth-telling rate in the uncorrelated preference environment, it also has a significantly negative effect on truth-telling adoption in the correlated preference environment.

As a result, the increase of truth-telling rate makes subjects more likely to coordinate on Pareto efficient stable outcome, thus increasing total welfare in the uncorrelated preference environment. However, in the correlated preference environment where incentive for playing truthfully is relatively weak, misrepresentation does not significantly affect stability and efficiency of the matching outcome. This probably explains why predecessors' experience does not promote truth-telling behavior in the correlated preference environment.

This study has considerable policy implications. The simplest way for policy makers to promote truth-telling behavior is, of course, to tell participants that truth-telling is the best strategy. For example, the Boston Public Schools advise parents and students to "list your school choices in your true order of preference" and that "there is no need to strategize." NRMP establishment also recommends a truthful revelation strategy to new physicians on their website. However, simply recommending people to follow truth-telling may not work well. In fact, people in reality commonly do not want to follow what officials tell them to do if are not give any convincing explanation. For example, Guillén and Hing (2013) study how third party advice can affect individual behavior in the Top Trading Cycle mechanism, another widely used strategy-proof matching mechanism which is as complex as the Deferred Acceptance mechanism. The advice is presented as follows:

"The mechanism is designed so that truthful reporting maximizes your chances of getting favored schools. You should rank the schools in order of their true value to you."

It turns out that truth-telling rate falls to $50 \%$ in this right advice treatment, compared to $73 \%$ in the baseline where subjects are not given any advice.

Since people in the field usually seek wisdom from people who have participated in previous matching markets, advice from peers who have experienced the market may be more likely to be accepted than advice from officials. I propose that policy makers can gather a group of people who have participated in the market, and invite them to give advice about the best strategies. 
The collected advice can be published on the official website of matching programs together with official recommendation, so as to provide a more convincing type of persuasion than just telling participants to play truthfully. 


\section{References}

Abdulkadiroğlu, A., Hu, W., and Pathak, P. (2013). Small high schools and student achievement: Lottery-based evidence from new york. Working paper.

Abdulkadiroğlu, A., Pathak, P. A., and Roth, A. E. (2005a). The new york city high school match. American Economic Review, 95(2):364-367.

Abdulkadiroğlu, A., Pathak, P. A., Roth, A. E., and Sönmez, T. (2005b). The boston public school match. American Economic Review, 95(2):368-371.

Attiyeh, G., Franciosi, R., and Isaac, R. M. (2000). Experiments with the pivot process for providing public goods. Public Choice, 102(1-2):95-114.

Azevedo, E. M. and Budish, E. (2012). Strategyproofness in the large as a desideratum for market design. Working Paper.

Brandts, J., Groenert, V., and Rott, C. The impact of advice on women's and men's selection into competition. Management Science, Forthcoming.

Budish, E. and Cantillon, E. (2012). The multi-unit assignment problem: Theory and evidence from course allocation at harvard. American Economic Review, 102(5):2237-71.

Calsamiglia, C., Haeringer, G., and Klijn, F. (2010). Constrained school choice: An experimental study. American Economic Review, 100(4):1860-74.

Cason, T. N., Saijo, T., Sjostrom, T., and Yamato, T. (2006). Secure implementation experiments: Do strategy-proof mechanisms really work? Games and Economic Behavior, 57(2):206-235.

Chaudhuri, A., Graziano, S., and Maitra, P. (2006). Social learning and norms in a public goods experiment with inter-generational advice. The Review of Economic Studies, 73(2):357-380.

Chaudhuri, A., Schotter, A., and Sopher, B. (2009). Talking ourselves to efficiency: Coordination in inter-generational minimum effort games with private, almost common and common knowledge of advice. Economic Journal, 119(534):91-122.

Chen, Y., Jiang, M., Kesten, O., Robin, S., and Zhu, M. (2014). Matching in the large: An experimental study. Working Paper.

Chen, Y. and Kesten, O. (2014). Chinese college admissions and school choice reforms: Theory and experiments. Working Paper. 
Chen, Y. and Sönmez, T. (2006). School choice: An experimental study. Journal of Economic Theory, 127(1):202-231.

Clarke, E. H. (1971). Multiple pricing of public goods. Public Choice, 11(1).

Ding, T. and Schotter, A. (2014). Matching and chatting: An experimental study of the impact of network communication on school-matching mechanisms. Working Paper.

Ding, T. and Schotter, A. (2015). Intergenerational Advice and Matching: An Experimental Study. Working Paper.

Dubins, L. E. and Freedman, D. A. (1981). Machiavelli and the Gale-Shapley algorithm. American Mathematical Monthly, 88:485-494.

Echenique, F., Wilson, A., and Yariv, L. (2014). Clearinghouses for two-sided matching: An experimental study. Working paper.

Featherstone, C. and Mayefsky, E. (2014). Why do some clearinghouses yield stable outcomes? experimental evidence on out-of-equilibrium truth-telling. Working Paper.

Featherstone, C. and Niederle, M. (2014). Improving on strategy-proof school choice mechanisms: An experimental investigation. Working Paper.

Fischbacher, U. (2007). z-tree: Zurich toolbox for ready-made economic experiments. Experimental Economics, 10(2):171-178.

Gale, D. and Shapley, L. S. (1962a). College admissions and the stability of marriage. American Mathematical Monthly, 69:9-15.

Gale, D. and Shapley, L. S. (1962b). College admissions and the stability of marriage. American Mathematical Monthly, 69:9-15.

Garratt, R., Walker, M., and Wooders, J. (2012). Behavior in second-price auctions by highly experienced eBay buyers and sellers. Experimental Economics, 15(1):44-57.

Groves, T. (1973). Incentives in teams. Econometrica, 41(4):617-631.

Guillén, P. and Hakimov, R. (2014). Monkey see, monkey do: truth-telling in matching algorithms and the manipulation of others. Working Papers 2014-01, University of Sydney, School of Economics. 
Guillén, P. and Hing, A. (2013). Lying through their teeth: Third party advice and truth telling in a strategy proof mechanism. Working Papers 2013-11, University of Sydney, School of Economics.

Harstad, R. (2000). Dominant strategy adoption and bidders' experience with pricing rules. Experimental Economics, 3(3):261-280.

Immorlica, N. and Mahdian, M. (2005). Marriage, honesty, and stability. In Proceedings of the Sixteenth Annual ACM-SIAM Symposium on Discrete Algorithms, SODA '05, pages 53-62, Philadelphia, PA, USA. Society for Industrial and Applied Mathematics.

Kagel, J. H., Harstad, R. M., and Levin, D. (1987). Information impact and allocation rules in auctions with affiliated private values: A laboratory study. Econometrica, 55(6):1275-1304.

Kagel, J. H. and Levin, D. (1993). Independent private value auctions: Bidder behaviour in first-, second- and third-price auctions with varying numbers of bidders. Economic Journal, 103(419):868-79.

Kagel, J. H. and Roth, A. E. (2000). The dynamics of reorganization in matching markets: A laboratory experiment motivated by a natural experiment. Quarterly Journal of Economics, 115(1):201-235.

Kawagoe, T. and Mori, T. (2001). Can the pivotal mechanism induce truth-telling? an experimental study. Public Choice, 108(3-4):331-54.

Klijn, F., Pais, J., and Vorsatz, M. (2013). Preference intensities and risk aversion in school choice: a laboratory experiment. Experimental Economics, 16(1):1-22.

Kojima, F. and Pathak, P. A. (2009). Incentives and stability in large two-sided matching markets. American Economic Review, 99:608-627.

Pais, J. and Pintér, Á. (2008). School choice and information: An experimental study on matching mechanisms. Games and Economic Behavior, 64(1):303-328.

Pathak, P. A. and Sönmez, T. (2008). Leveling the playing field: Sincere and sophisticated players in the boston mechanism. The American Economic Review, 98(4):1636-1652.

Roth, A. E. (1982). The economics of matching: Stability and incentives. Mathematics of Operations Research, 7(4):617-628.

Roth, A. E. (1984). The evolution of labor market for medical interns and residents: A case study in game theory. Journal of Political Economy, 92:991-1016. 
Roth, A. E. (1991). A natural experiment in the organization of entry-level labor markets: Regional markets for new physicians and surgeons in the united kingdom. American Economic Review, 81(3):414-440.

Roth, A. E. (2008). What have we learned from market design? Economic Journal, 118(527):285310.

Roth, A. E. and Peranson, E. (1999). The redesign of the matching market for american physicians: Some engineering aspects of economic design. American Economic Review, 89(4):748-780.

Schotter, A. (2003). Decision making with naive advice. American Economic Review, 93(2):196201.

Schotter, A. and Sopher, B. (2003). Social learning and coordination conventions in intergenerational games: An experimental study. Journal of Political Economy, 111(3):498-529.

Schotter, A. and Sopher, B. (2006). Trust and trustworthiness in games: An experimental study of intergenerational advice. Experimental Economics, 9(2):123-145.

Schotter, A. and Sopher, B. (2007). Advice and behavior in intergenerational ultimatum games: An experimental approach. Games and Economic Behavior, 58(2):365-393.

Sjostrom, T., Yamato, T., and Saijo, T. (2007). Secure implementation. Theoretical Economics, 2(3):203-229.

Vickrey, W. (1961). Counterspeculation, auctions, and competitive sealed tenders. Journal of Finance, 16(1):8-37. 


\section{Appendix: Instruction (Translated From French)}

The complete instruction for the baseline treatment in uncorrelated preference environment is shown here. The instruction for the baseline treatment in correlated preference environment is identical except for the payoff table; instructions for the advice treatment and observation treatments in either environment are identical to the baseline treatment except that there is additional page with the information of the baseline treatment. Hence, only different part for other instructions are presented here.

\section{Instructions for the Baseline Treatment in Uncorrelated Preference Environ- ment}

This is the instruction for the main experiment. After the main experiment, you are also invited to make some additional tasks. We will give you the instructions for these tasks after you finish the main experiment.

This is an experiment in the economics of decision making. In this experiment, you will participate in a procedure to obtain an object valuable for you. The procedure and allocation method are described below. The amount of money you earn will depend upon the decisions you make and on the decisions other participants make. Do not communicate with each other during the experiment. If you have questions at any point during the experiment, raise your hand and the experimenter will help you. At the end of the instructions, you will be asked to provide answers to a series of review questions. Once everyone has finished the review questions, we will go through the answers together.

\section{Procedure}

- There are 12 participants of 3 different types in this experiment. Your type remains the same throughout the experiment. Your type will be shown on your computer screen.

- The experiment consists of 15 periods. In each period, you will be randomly matched with 2 other participants in the room to form a group of 3. Your earning for each period depends on your choices as well as the choices of the other 2 participants in your group. Each group contains 3 different types.

- In this experiment, there are 3 different objects A, B and C to be allocated for each group. Each object is allocated to one participant.

- Each type of subjects have different priorities for each object allocated to them, which is shown as follows: 


\begin{tabular}{c|ccc}
\hline \hline Object & 1st Priority & 2nd Priority & 3rd Priority \\
A & Type3 & Type2 & Type1 \\
B & Type1 & Type3 & Type2 \\
C & Type2 & Type1 & Type3 \\
\hline \hline
\end{tabular}

For allocation of object A, Type 3 is ranked first, Type 2 is ranked second, and Type 1 is ranked third;

For allocation of object B, Type 1 is ranked first, Type 3 is ranked second, and Type 2 is ranked third;

For allocation of object C, Type 2 is ranked first, Type 1 is ranked second, and Type 3 is ranked third.

- Your payoff amount depends on the object allocated to you at the end of each period. Payoff amount for 3 types of subjects are outlined in the following table.

\begin{tabular}{c|ccc}
\hline \hline & Object A & Object B & Object C \\
Type1 & 200 & 120 & 40 \\
Type2 & 40 & 200 & 120 \\
Type3 & 120 & 40 & 200 \\
\hline \hline
\end{tabular}

The object allocated to you and your payoff has the following relation:

If you are Type 1 student:

You will be paid 200 points if object A is allocated to you at the end of a period. You will be paid 120 points if object B is allocated to you at the end of a period. You will be paid 40 points if object $\mathrm{C}$ is allocated to you at the end of a period.

The same goes for other types.

- Every period, you are asked to submit a choice list indicating which object is your first choice, which object is your second choice, and which object is your third choice. Note that you need to list all 3 objects, and you can indicate whatever choice list you like.

- In each period, after all participants make submissions, the objects will be allocated within each group by the server according to certain allocation method, which we will describe later. Then each participant will be informed which object is allocated to him/her and respective payoff. Note that in each period the allocation process is independent from each other.

\section{Payment}


- The computer will randomly select 1 period out of all 15 periods, and your final payment is the payoff you earned in this randomly selected period. That is, the payoff you earned in each period has an equal probability to be selected as your final payment. We will inform you the selected period and the relevant payoff at the end of the whole experiment.

- Your earnings are given in points. At the end of the experiment you will be paid based on the exchange rate,

\section{1 euro $=20$ points. \\ Or \\ 1 point $=0,05$ euro.}

You will be paid 5 points for answering each Review Question correctly.

In addition, you will be paid 3 euro for participation. Everyone will be paid in private at the end of experiment and you are under no obligation to tell others how much you earn.

Are there any question?

\section{Allocation Method}

- After all subjects make submissions, the server will start the allocation according to the following method which consists of several steps:

Step1: * Each subject is selected to be sent to the object which he/she indicates as first choice.

* For each object, all subjects who put it as first choice are ranked according to their priorities for this object. The object is temporarily allocated to the subject who has the highest priority.

* The remaining subjects are rejected.

Step2: * Each subject rejected at Step 1 is sent to the object which he/she indicates as next choice.

* $\quad$ For each object, the server will pool together the subjects who are sent to it at Step 2 and the subjects whom it is temporarily allocated to at Step 1. All pooled subjects are ranked together according to their priorities for this object. Then the object is temporarily allocated to the subject who has the highest priority.

* The remaining subjects are rejected.

The process continues until there is no subject being rejected. Then all temporary allocations become permanent.

\section{An example:}


We will go through an example to illustrate how the allocation method works. You will be asked to work out the allocation of this example for Review Question 1. There are 4 blank spaces to fill in on the computer screen. You will be given 5 points for entering each correct answer in each space.

Notice: this example is only used to illustrate how the allocation method works, not for actual experiment. In this example, there are 4 types of subjects, and 4 different objects, A, B, C and D.

\begin{tabular}{|l|l|}
\hline Student ID number: $1,2,3,4$ & Objects: A, B, C, D \\
\hline
\end{tabular}

Subject's priorities for each object are indicated in the table below.

\begin{tabular}{c|cccc}
\hline \hline Object & 1st Priority & 2nd Priority & 3rd Priority & 4th Priority \\
\hline A & 3 & 2 & 4 & 1 \\
B & 2 & 4 & 1 & 3 \\
C & 4 & 1 & 3 & 2 \\
D & 1 & 3 & 2 & 4 \\
\hline \hline
\end{tabular}

Subjects submit following lists for objects:

\begin{tabular}{c|cccc}
\hline \hline Subject & 1st Choice & 2nd Choice & 3rd Choice & 4th Choice \\
\hline 1 & $\mathrm{~A}$ & $\mathrm{D}$ & $\mathrm{C}$ & $\mathrm{B}$ \\
2 & $\mathrm{~A}$ & $\mathrm{~B}$ & $\mathrm{C}$ & $\mathrm{D}$ \\
3 & $\mathrm{D}$ & $\mathrm{B}$ & $\mathrm{A}$ & $\mathrm{C}$ \\
4 & $\mathrm{D}$ & $\mathrm{A}$ & $\mathrm{C}$ & $\mathrm{B}$ \\
\hline \hline
\end{tabular}

The allocation method consists of the following steps. To work out the allocation, please follow the steps of this sheet and fill out the blank cell about the allocation result in each step (that is, to which subject the object is temporarily allocated and which subject is rejected). The result of "Permanent Allocate" cell in the last table is the final allocation outcome. Please enter it into the computer for Review Question 1.

Step 1: Each subject is sent to the object which he/she indicates as first choice. For each object, all subjects who put it as first choice are ranked according to their priorites for this object. The object is temporarily allocated to the subject who has the highest priority. The remaining subjects are rejected. 


\begin{tabular}{cl|c|lrl} 
Subject & & Object & & Temporarily Allocate & Reject \\
\hline 1,2 & $\longrightarrow$ & $\mathrm{A}$ & $\longrightarrow$ & \\
& & $\mathrm{B}$ & & \\
$\mathrm{C}$ & & & \\
3,4 & $\longrightarrow$ & $\mathrm{D}$ & $\longrightarrow$ & \\
\hline
\end{tabular}

Step 2: Each subject rejected at Step 1 is sent to the object which he/she indicates as next choice. For each object, the server will pool together the subjects who are sent to it at Step 2 and the subjects whom it is temporarily allocated to at Step 1. All pooled subjects are ranked together according to their priorites for this object. Then the object is temporarily allocated to the subject who has the highest priority, and the rest are rejected.

\begin{tabular}{l|l|lc|lcc} 
Temporarily Allocate & New Subject & & Object & & Temporarily Allocate Reject \\
\hline & & $\longrightarrow$ & A & $\longrightarrow$ & & \\
& & $\longrightarrow$ & B & $\longrightarrow$ & & \\
& & $\longrightarrow$ & D & $\longrightarrow$ & & \\
& & & D & $\longrightarrow$ &
\end{tabular}

Step 3: Each subject rejected in Step 2 is sent to his/her next choice. No one is rejected at this step. Temporary allocations in Step 2 become permanent allocations.

\begin{tabular}{l|l|lc|lcc} 
Temporarily Allocate & New Subject & & Object & & Temporarily Allocate Reject \\
\hline & & $\longrightarrow$ & A & $\longrightarrow$ & & \\
& & $\longrightarrow$ & B & $\longrightarrow$ & & \\
& & $\longrightarrow$ & C & $\longrightarrow$ & & \\
& & & D & $\longrightarrow$ &
\end{tabular}

The allocation process terminates at the end of step 3 .

- Please enter your answer to the computer for Review Question 1. After all have entered their answers, we will distribute an answer sheet and go through the answer together.

- Feel free to refer to the experimental instruction before you answer any question.

\section{Part 2.}

Thank you for participation in this decision making problem, now you have finished Part 1. The computer will randomly select 1 out of 15 periods, and uses the payoff you earned in that period as your final payment. The calculation will be conducted at the end of the whole session and the selected period and relevant payoff will be shown to you on the computer screen later. Before finishing the whole session, you are also asked to make some tasks, and you will earn additional payment for decisions you make in these tasks. 
- Next, you are invited to give advice on how to make decisions to a group of participants who will participant in the same experiments in the following weeks.

- The form of this advice is simple. You simply suggest an action: which object should be the first choice, the second choice, and the third choice. Or you are also free to give no advice on the computer screen. You will enter it in the space shown on the computer screen.

- You will receive the additional payment which is $20 \%$ of the average groups earning who receive your advice in Part 1 (do not include show up fee and quiz earnings). That is, you will earn $20 \%$ of the average total payment of a group computed over the 15 periods for all group of participants.

- We will send you email in the following weeks about your additional payment, and you can pick up the money at the office \#20 of GATE.

\section{Instructions for the Baseline Treatment in Correlated Preference Environ- ment}

- Your payoff amount depends on the object allocated to you at the end of each period. Payoff amount for 3 types of subjects are outlined in the following table.

\begin{tabular}{c|ccc}
\hline \hline & Object A & Object B & Object C \\
Type1 & 200 & 120 & 40 \\
Type2 & 200 & 40 & 120 \\
Type3 & 120 & 200 & 40 \\
\hline \hline
\end{tabular}

The object allocated to you and your payoff has the following relation:

If you are Type 1 student:

You will be paid 200 points if object A is allocated to you at the end of a period. You will be paid 120 points if object B is allocated to you at the end of a period. You will be paid 40 points if object $\mathrm{C}$ is allocated to you at the end of a period.

The same goes for other types. 


\section{Instructions for the Advice Treatment in Uncorrelated Preference Environ- ment}

\section{$(\ldots \ldots)$}

Some people have already participated the same experiment as you a few weeks ago. These participants have the similar social demographic characteristics as participants who come to today's experiment. At the end of the experiment, these participants were asked to offer advice for upcoming participants. Specifically, each participant was invited to give advice on which choice list of objects should be submitted to participant who has the same type as himself. They are also given additional payment by giving such advice.

Please find below the instructions that were given to the participants of previous experiments:

"Next, you are invited to give advice on how to make decisions to a group of participants who will participant in the same experiments in the following weeks. The form of this advice is simple. You simply suggest an action: which object should be the first choice, the second choice, and the third choice. Or you are also free to give no advice on the computer screen. You will enter it in the space shown on the computer screen. You will receive the additional payment which is $20 \%$ of the average groups earning who receive your advice in Part 1 (do not include show up fee and quiz earnings). That is, you will earn $20 \%$ of the average total payment of a group computed over the 15 periods for all group of participants."

You are not invited to give advice in this session like them. Therefore, you will not have additional payment by giving advice like them. In order to make sure you have similar payment as those who have chance to give advice. We will pay you 3 euros in addition.

The advice that each of subjects given to each type is shown in the following table.

\begin{tabular}{lclclc}
\hline \multicolumn{2}{c}{ Type 1 } & \multicolumn{2}{c}{ Type 2 } & \multicolumn{2}{c}{ Type 3 } \\
\hline $\mathrm{A}=200 ; \mathrm{B}=120 ; \mathrm{C}=40$ & $\mathrm{~A}=40 ; \mathrm{B}=200 ; \mathrm{C}=120$ & $\mathrm{~A}=120 ; \mathrm{B}=40 ; \mathrm{C}=200$ \\
$\mathrm{ABC}$ & $91.67 \%$ & $\mathrm{ABC}$ & $0 \%$ & $\mathrm{ABC}$ & $0 \%$ \\
$\mathrm{ACB}$ & $0 \%$ & $\mathrm{ACB}$ & $0 \%$ & $\mathrm{ACB}$ & $16.67 \%$ \\
$\mathrm{BAC}$ & $0 \%$ & $\mathrm{BAC}$ & $8.33 \%$ & $\mathrm{BAC}$ & $0 \%$ \\
$\mathrm{BCA}$ & $0 \%$ & $\mathrm{BCA}$ & $83.33 \%$ & $\mathrm{BCA}$ & $0 \%$ \\
$\mathrm{CAB}$ & $8.33 \%$ & $\mathrm{CAB}$ & $0 \%$ & $\mathrm{CAB}$ & $75 \%$ \\
$\mathrm{CBA}$ & $0 \%$ & $\mathrm{CBA}$ & $8.33 \%$ & $\mathrm{CBA}$ & $8.33 \%$ \\
\hline
\end{tabular}

Exemple : (Please look at the last row of the table) 
- $0 \%$ of previous participants of type 1 suggest participants of type 1 to list object $\mathrm{C}$ as first choice, object B as second choice and object A as third choice.

- $8.33 \%$ of previous participants of type 2 suggest participants of type 2 to list object $\mathrm{C}$ as first choice, object B as second choice and object A as third choice.

- $8.33 \%$ of previous participants of type 3 suggest participants of type 3 to list object $\mathrm{C}$ as first choice, object B as second choice and object A as third choice.

\section{Instructions for the Advice Treatment in Correlated Preference Environment}

\section{$(\ldots .$.}

The advice that each of subjects given to each type is shown in the following table.

\begin{tabular}{lclclc}
\hline \multicolumn{2}{c}{ Type 1 } & \multicolumn{2}{c}{ Type 2 } & \multicolumn{2}{c}{ Type 3 } \\
\hline $\mathrm{A}=200 ; \mathrm{B}=120 ; \mathrm{C}=40$ & $\mathrm{~A}=200 ; \mathrm{B}=40 ; \mathrm{C}=120$ & $\mathrm{~A}=120 ; \mathrm{B}=200 ; \mathrm{C}=40$ \\
$\mathrm{ABC}$ & $66,67 \%$ & $\mathrm{ABC}$ & $8,33 \%$ & $\mathrm{ABC}$ & $16,67 \%$ \\
$\mathrm{ACB}$ & $0 \%$ & $\mathrm{ACB}$ & $75 \%$ & $\mathrm{ACB}$ & $0 \%$ \\
$\mathrm{BAC}$ & $25 \%$ & $\mathrm{BAC}$ & $8,33 \%$ & $\mathrm{BAC}$ & $83,33 \%$ \\
$\mathrm{BCA}$ & $8,33 \%$ & $\mathrm{BCA}$ & $0 \%$ & $\mathrm{BCA}$ & $0 \%$ \\
$\mathrm{CAB}$ & $0 \%$ & $\mathrm{CAB}$ & $0 \%$ & $\mathrm{CAB}$ & $0 \%$ \\
$\mathrm{CBA}$ & $0 \%$ & $\mathrm{CBA}$ & $8,33 \%$ & $\mathrm{CBA}$ & $0 \%$ \\
\hline
\end{tabular}

Exemple : (Please look at the last row of the table)

- $0 \%$ of previous participants of type 1 suggest participants of type 1 to list object $\mathrm{C}$ as first choice, object B as second choice and object A as third choice.

- $8.33 \%$ of previous participants of type 2 suggest participants of type 2 to list object $\mathrm{C}$ as first choice, object B as second choice and object $\mathrm{A}$ as third choice.

- $0 \%$ of previous participants of type 3 suggest participants of type 3 to list object $\mathrm{C}$ as first choice, object B as second choice and object A as third choice. 


\section{Instructions for the Observe Treatment in Uncorrelated Preference Environ- ment}

\section{$(\ldots \ldots)$}

Some people have already participated the same experiment as you a few weeks ago. These participants have the similar social demographic characteristics as participants who come to today's experiment. At the end of the experiment, you will be paid additional 3 euros for questionnaire part.

For each type of previous participants, their submitted choice lists and average payments from period $1-15$ are shown in the following tables.

\begin{tabular}{lcccccc}
\hline \multicolumn{7}{c}{ Type 1 } \\
\hline \multicolumn{7}{c}{ A $=200 ; \mathrm{B}=120 ; \mathrm{C}=40$} \\
ABC & ACB & BAC & BCA & CAB & CBA \\
Period 1 & 200 & & 120 & 120 & 120 & \\
Period 2 & 173 & 120 & 120 & 120 & & \\
Period 3 & 168 & & 120 & 120 & 200 & 120 \\
Period 4 & 182 & & 120 & 120 & & \\
Period 5 & 180 & & 120 & & 93 & \\
Period 6 & 182 & 200 & 120 & & 120 & \\
Period 7 & 182 & 200 & 120 & 120 & & \\
Period 8 & 168 & 120 & 120 & & & \\
Period 9 & 176 & & 120 & 120 & & \\
Period 10 & 186 & & 120 & & & \\
Period 11 & 173 & & & & 40 & \\
Period 12 & 186 & & & & & \\
Period 13 & 186 & 40 & & & 40 & \\
Period 14 & 186 & & & & & \\
Period 15 & 186 & \multicolumn{7}{c}{120} & & \\
\hline
\end{tabular}

Exemple : In period 1, participants of type 1 on average earn 120 points by submitting object $\mathrm{B}$ as first choice, object $\mathrm{C}$ as second choice, and object $\mathrm{A}$ as third choice. 


\begin{tabular}{|c|c|c|c|c|c|}
\hline \multicolumn{6}{|c|}{ Type 2} \\
\hline \multicolumn{6}{|c|}{$\mathrm{A}=40 ; \mathrm{B}=200 ; \mathrm{C}=120$} \\
\hline & $\mathrm{ABC} \quad \mathrm{ACB}$ & BAC & $\mathrm{BCA}$ & $\mathrm{CAB}$ & CBA \\
\hline Period 1 & & & 140 & 120 & 120 \\
\hline Period 2 & & & 160 & & 120 \\
\hline Period 3 & 40 & 120 & 147 & & 120 \\
\hline Period 4 & & 40 & 173 & 120 & 120 \\
\hline Period 5 & & 200 & 173 & 120 & 120 \\
\hline Period 6 & & 200 & 180 & 120 & 120 \\
\hline Period 7 & & 200 & 182 & 120 & \\
\hline Period 8 & 120 & 200 & 170 & 120 & 120 \\
\hline Period 9 & 40 & 160 & 177 & & 120 \\
\hline Period 10 & 120 & 200 & 191 & & 120 \\
\hline Period 11 & 40 & 200 & 182 & 120 & \\
\hline Period 12 & & 200 & 182 & & 120 \\
\hline Period 13 & & 200 & 192 & & 120 \\
\hline Period 14 & & 200 & 192 & & 120 \\
\hline Period 15 & & 200 & 184 & 120 & \\
\hline
\end{tabular}

Exemple : In period 1, participants of type 2 on average earn 140 points by submitting object B as first choice, object $\mathrm{C}$ as second choice, and object $\mathrm{A}$ as third choice.

\begin{tabular}{lcccccc}
\hline \multicolumn{7}{c}{ Type 3 } \\
\hline \multicolumn{7}{c}{ A $=120 ; \mathrm{B}=40 ; \mathrm{C}=200$} \\
ABC & ACB & BAC & BCA & CAB & CBA \\
Period 1 & 120 & 120 & 40 & 120 & 147 & \\
Period 2 & 120 & 120 & & 40 & 143 & 200 \\
Period 3 & 120 & 120 & 40 & & 166 & 160 \\
Period 4 & & 120 & 40 & & 189 & 160 \\
Period 5 & 120 & 120 & & 40 & 166 & 120 \\
Period 6 & & 120 & & 40 & 170 & 200 \\
Period 7 & 120 & & & & 176 & 200 \\
Period 8 & 120 & 120 & & & 170 & 200 \\
Period 9 & 120 & 120 & & & 182 & 40 \\
Period 10 & 120 & 120 & & & 191 & 200 \\
Period 11 & 120 & 120 & & & 191 & 200 \\
Period 12 & 120 & 120 & & 40 & 190 & 200 \\
Period 13 & & 120 & & & 191 & 200 \\
Period 14 & & 120 & & & 191 & 200 \\
Period 15 & & 120 & & & 191 & 200 \\
\hline
\end{tabular}

Exemple : In period 1, participants of type 3 on average earn 120 points by submitting object B as first choice, object $\mathrm{C}$ as second choice, and object $\mathrm{A}$ as third choice. 


\section{Instructions for the Observe Treatment in Correlated Preference Environ- ment}

\section{$(\ldots \ldots)$}

Some people have already participated the same experiment as you a few weeks ago. These participants have the similar social demographic characteristics as participants who come to today's experiment. At the end of the experiment, you will be paid additional 3 euros for questionnaire part.

For each type of previous participants, their submitted choice lists and average payments from period $1-15$ are shown in the following tables.

\begin{tabular}{ccccccc}
\hline \multicolumn{7}{c}{ Type 1 } \\
\hline \multicolumn{7}{c}{ A $=200 ; \mathrm{B}=120 ; \mathrm{C}=40$} \\
& ABC & ACB & BAC & BCA & CAB & CBA \\
Period 1 & 120 & & 120 & 120 & 120 & \\
Period 2 & 133 & & 120 & 120 & 40 & \\
Period 3 & 140 & & 120 & 120 & 40 & 40 \\
Period 4 & 131 & & 120 & 120 & 40 & \\
Period 5 & 140 & 67 & 120 & 120 & & \\
Period 6 & 147 & & 120 & 120 & & \\
Period 7 & 129 & & 120 & 120 & & \\
Period 8 & 128 & & & 120 & & \\
Period 9 & 129 & & 120 & 120 & & \\
Period 10 & 129 & & 120 & 120 & & \\
Period 11 & 120 & 200 & 120 & 120 & & \\
Period 12 & 129 & & 120 & 120 & & \\
Period 13 & 120 & & 120 & 120 & & \\
Period 14 & 120 & 40 & 120 & 120 & & \\
Period 15 & 130 & & 120 & 120 & 120 & \\
\hline
\end{tabular}

Exemple : In period 1, participants of type 1 on average earn 120 points by submitting object $\mathrm{C}$ as first choice, object A as second choice, and object B as third choice. 


\begin{tabular}{lcccccc}
\hline \multicolumn{7}{c}{ Type 2 } \\
\hline \multicolumn{7}{c}{ A $=200 ; \mathrm{B}=40 ; \mathrm{C}=120$} \\
& ABC & ACB & BAC & BCA & CAB & CBA \\
Period 1 & & 131 & & & 120 & \\
Period 2 & & 150 & 120 & & 120 & \\
Period 3 & 120 & 140 & 120 & & 120 & \\
Period 4 & & 120 & 200 & & 120 & 120 \\
Period 5 & 200 & 168 & 120 & & 120 & \\
Period 6 & & 150 & 120 & 120 & 120 & \\
Period 7 & 120 & 120 & & & 120 & \\
Period 8 & & 120 & 120 & & & 120 \\
Period 9 & & 120 & 120 & & 120 & \\
Period 10 & 120 & 129 & 120 & 120 & & \\
Period 11 & 120 & 120 & & & & 120 \\
Period 12 & 120 & 120 & 120 & 120 & & \\
Period 13 & & 120 & & & & 120 \\
Period 14 & 160 & 138 & 120 & & & \\
Period 15 & 120 & 120 & & & & 120 \\
\hline
\end{tabular}

Exemple : In period 1, participants of type 2 on average earn 120 points by submitting object $C$ as first choice, object A as second choice, and object B as third choice.

\begin{tabular}{ccccccc}
\hline \multicolumn{7}{c}{ Type 3 } \\
\hline \multicolumn{7}{c}{ A $=120 ; \mathrm{B}=200 ; \mathrm{C}=40$} \\
ABC & ACB & BAC & BCA & CAB & CBA \\
Period 1 & 120 & 120 & & & & 40 \\
Period 2 & 120 & 140 & & 40 & & 40 \\
Period 3 & 120 & 150 & & & & \\
Period 4 & 120 & 131 & & & 120 & 200 \\
Period 5 & 120 & 160 & & & 40 \\
Period 6 & 120 & 150 & & 40 & 40 \\
Period 7 & 120 & 128 & & & \\
Period 8 & 120 & 129 & & & \\
Period 9 & 120 & 127 & & & 40 \\
Period 10 & 120 & 128 & & & \\
Period 11 & 120 & 127 & & & \\
Period 12 & 120 & 128 & & & \\
Period 13 & 120 & 120 & & & \\
Period 14 & 120 & 129 & & & \\
Period 15 & 120 & 128 & & & \\
\hline
\end{tabular}

Exemple : In period 1, participants of type 3 on average earn 120 points by submitting object $A$ as first choice, object $\mathrm{C}$ as second choice, and object $\mathrm{B}$ as third choice. 